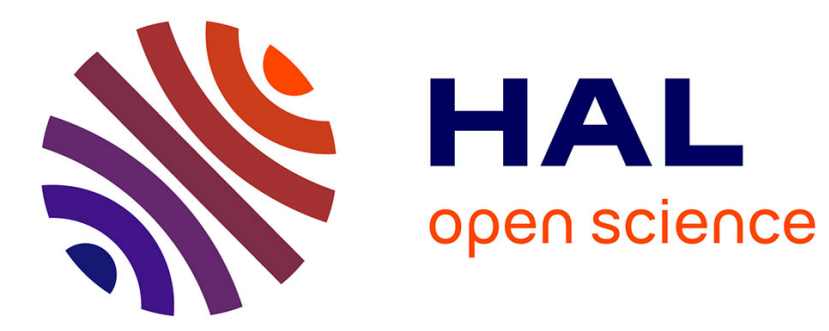

\title{
À propos de la corpulence des bovins en France durant les périodes historiques
}

Vianney Forest, Isabelle Rodet-Belarbi

\section{To cite this version:}

Vianney Forest, Isabelle Rodet-Belarbi. À propos de la corpulence des bovins en France durant les périodes historiques. Gallia - Archéologie de la France antique, 2002, 59, pp.273-306. 10.3406/galia.2002.3053 . halshs-00422963

\section{HAL Id: halshs-00422963 https://shs.hal.science/halshs-00422963}

Submitted on 20 Jan 2020

HAL is a multi-disciplinary open access archive for the deposit and dissemination of scientific research documents, whether they are published or not. The documents may come from teaching and research institutions in France or abroad, or from public or private research centers.
L'archive ouverte pluridisciplinaire HAL, est destinée au dépôt et à la diffusion de documents scientifiques de niveau recherche, publiés ou non, émanant des établissements d'enseignement et de recherche français ou étrangers, des laboratoires publics ou privés.

\section{(ㅇ)(1) $\$$}

Distributed under a Creative Commons Attribution - NonCommercial - NoDerivatives $\mid 4.0$ 


\title{
À PROPOS DE LA CORPULENCE DES BOVINS EN FRANCE DURANT LES PÉRIODES HISTORIQUES
}

\author{
Vianney FOREST* et Isabelle RODET-BELARBI**
}

Mots-clés. Archéozoologie, ostéométrie, mélatarse, Gaule romaine, Moyen Âge, bovins, élevage.

Key-words. Archaeozoology, osteometry, metatarsal bone, Roman Gaul, Middle Ages, callle, breeding.

Résumé. I es variations de la corpulence des bovins sont examinées sur une période chronologique longue s’étendant de la conquête romaine aux Temps modernes, à l'aide d'un large corpus de données sur la France, à travers l'observation comparée des mesures brutes Glun os : le métatarse. Les résultats amènent à réfléchir sur les mécanismes biologiques el zootechniques mobilisés avamt d'en troutuer les origines socio-économiques. Les idées communément admises, comme l'importation de grands bovins par les Romains, la réapparition d'un petit bovin durant tout le Moyen Âge et un accroissement de son format atyec la Renaissance, sont confronlées aux résultats Ille registrés lors de ce recensement ostéométrique qui constitue en lui-même une nouveaulé pour la France.

A.bstract. Variations of the bovine size are examined from the Roman Conquest to the XVIII' century in France, through a large census of osteometric data concerning the metalarsus. Results of the diachronic observations of the raw measures lead us to consider the biologic and breeding mechanisms before finding the socio-economic reasons of these variations. The hypothesis zuhich suggests the import of large

${ }_{0}^{ \pm}$Roman bovines from. Rome or another Italian centre, the presence of a little bovine during the Middle Ages who has growed up during the Renaissance, are confronted to results of this census which constitules in himself a novelty for France.

La fluctuation de la taille des bovins ' entre l'époque gauloise et le $\mathrm{XX}^{\prime \prime} \mathrm{s}$. a ouvert aux archéozoologues un vaste champ de recherches. Au-delà du mode d'enregistrement ostéométrique usité pour mettre en évidence les variations selon les périodes chronologiques, le débat s'étend largement et prend place aussi bien dans le domaine biologique qu'historique. Pour la période romaine, les interrogations se portent sur l'existence ou non d'un ou de plusieurs morphotypes de bovins en
Gaule et sur l'importation ou non d'un " grand bœuf romain ", ainsi que sur les motivations qui ont poussé aux modifications de la corpulence de ces animaux durant le ${ }^{\mathrm{I}}{ }^{\mathrm{er}} \mathrm{s}$. de notre ère. Résultent-elles d'une volonté politique d'imposer un nouveau bétail aux éleveurs de la Gaule récemment conquise ou d'une nécessité économique, celle d'accroître le rendement du cheptel par le biais d'une meilleure gestion zootechnique pour, par exemple, fournir de la viande en grande quantité aux

* Docteur vétérinaire, chargé d'études à l'INRAP, membre associé au Centre d’anthropologie, UMR 8555, 39 allées Jules-Guesde, F-31000) Toulouse. ** Ingénieur INRAP, chercheur associé au laboratoire d archéozoologie du (ÉPA.M-LMR 6130 du (NRS, Sophia Antipolis, F-06560) Valbomne.

1. Dans cet article, le terme "bovin " est réscrvé à l'espèce domestique car aucun reste de bison (Bison bonasus) n’a ćté recensé pour les périodes historiques en Europe occidentale (Audoin-Rouzeau, 1993). Il en est de même pour l'aurochs (Bos primignnius), à l'exception d'un squelette daté de l'époque gallo-romaine, mis au jour dans le Jura gessien à plus de $1000 \mathrm{~m}$ d'altitude (Chaix, 1984), et d'une extrémité distale de métatarse à Aulnayde-Saintonge (Charente-Maritime) mise au jour dans un niveau daté du $\mathrm{I}^{\mathrm{rr}}$ s. de notre ère (Lignereux, Peters, 1997a, p. 283 et 1997h, p. 400$)$. 


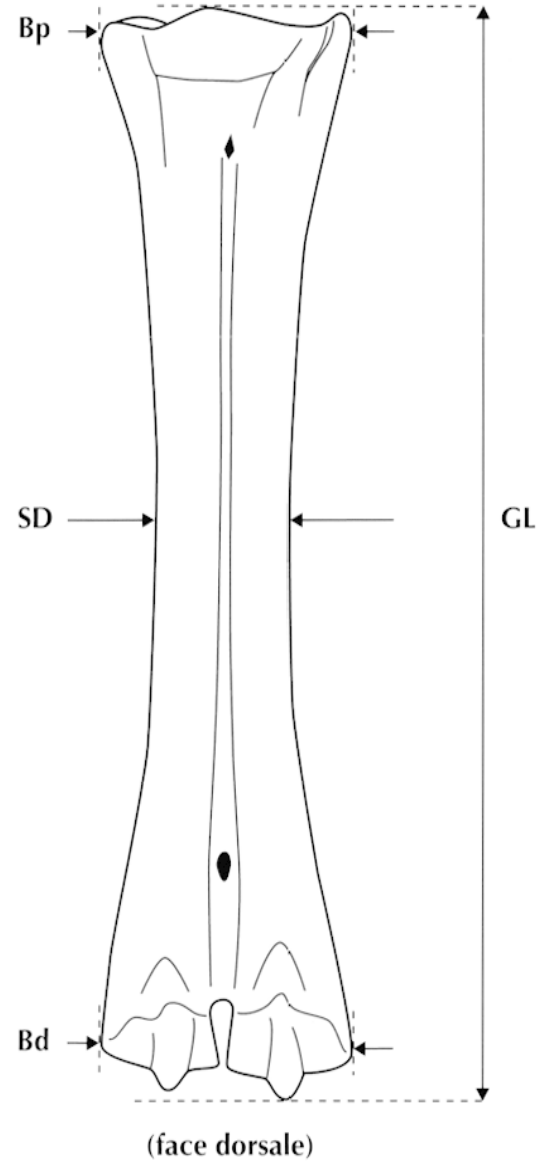

Fig. 1 - Mesures du métatarse de bovin : (sl, grande longueur; $B p$, largeur proximale; $S D$, diamètre diaphyse; Bd, largenu distale (I)AO V. Foresl, INRAP, d'après Driesch, 1976).

agglomérations en pleine expansion ? Les progrès zootechniques ont-ils été acquis par apprentissage volontaire de techniques d'élevage auprès de colons, ou par simple imitation plus ou moins habile ? Durant le haut Moyen Âge, la diminution de la corpulence des bovins a-t-elle été provoquée par une dégradation des compétences zootechniques des éleveurs ? Est-elle la marque de la disparition du " grand bouf romain » et du retour du " petit bœuf gaulois "? Ou encore, est-elle la conséquence de l'émiettement du pouvoir politique ? La persistance de petits bovins jusqu'à la fin du Moyen Âge est-elle due à l'extension des terres céréalières qui a réduit les aires de pâture ? Comment expliquer la nouvelle augmentation de la corpulence à l'extrême fin du Moyen Âge ? Sont-ce les prémisses de la Renaissance et des Temps modernes ?... Ces quelques questions, glanées dans des communications écrites ou orales, donnent un aperçu de la problématique soulevée par la variation de la corpulence des bovins.
Dans le travail présenté ici, synthèse de plusieurs études que nous avons menées (Forest, Rodet-Belarbi, 1997, 1998, 2000 ; Forest, à paraitre), nous avons décidé de regrouper un maximum de données métriques brutes concernant la longueur et les largeurs du métatarse (fig. 1), qui permettent d'appréhender l'animal dans ses trois dimensions. Afin d'en suivre les évolutions diachroniques, nous avons placé ces mesures dans des tableaux dont l'organisation autorise une lecture fine des événements, puisqu'ils exposent une grande part de l'information factuelle. Ainsi, pour partie au moins, nous pouvons proposer des réponses mieux ajustées aux questions énoncées ci-dessus.

\section{LES VARIATIONS DE LA CORPULENCE DES BOVINS ET LEURS CAUSES : LES HYPOTHĖSES EN PRÉSENCE}

Parmi les premières ćtudes recensées, celles de P. Revilliod (1926a et b) ${ }^{2}$ récapitulent les observations effectuées à cette époque. Les bovins sont classés en deux catégories : le petit bouf gaulois (Bos taurus brachyceros Rütimeyer) et le grand bœuf romain (Bos taurus brachycephalus Wilckens). L'auteur en conclut " qu'il est vraisemblable que les Romains aient croisé la race qu'ils avaient introduite avec celle qu'ils trouvèrent sur place [...] » (Revilliod, 1926b, p. 117) ${ }^{3}$, affirmant ainsi que deux morphotypes de bovins ont coexisté.

La multiplication des études archéozoologiques ${ }^{4}$ des vingt-cinq dernières années a relancé les investigations sur ce thème. Dans son étude du volumineux dépôt de vestiges osseux trouvé dans le port antique de Marseille et

2. P. Revilliod cite d'autres travaux antérieurs, en particulier ceux de Wilckens (1878), Kracmer (1900)...

3. Cet auteur rappelle que " C. Keller a aussi observé dans la couche supérieure de La Tène parmi les os de bovidés des formes intermédiaires" (ibid., note 1).

4. Seules les études les plus importantes et déterminantes pour ce débat sont mentionnées ici. Cette liste n'est ni exhaustive ni limitative. I a quasi-totalité des résultats mentionnés est fondée sur des hauteurs au garrot issues de la conversion interprétative des longueurs d'os longs et, pour certains d'entre eux, sur des diagrammes fournis par les mesures des phalanges proximales dont les interprétations biologiques préliminaires, fort délicates à mener (par exemple la position antérieure ou postérieure de l'os qui induit une morphologie sensiblement différente) (Dottrens, 1946), sont quasi inexistantes (Méniel, in Guilhot et al., 1992 ; Lepetz ef al., 1998, etc.). 
appartenant pour l'essentiel à une période allant du III au $V^{*}$ s. de notre ère, L. Jourdan reprend la thèse de Revilliod, mais affirme qu'à partir de la forme des cornillons " il est difficile de faire entrer dans cette classification les types rencontrés sur le gisement » (Jourdan, 1976, p. 116). L'analyse ostéométrique lui permet de conclure " qu'il peut avoir existé à Marseille une population double, qui se serait quelque peu métissée " composée d'animaux se rapportant aux deux groupes de Revilliod (ibid.). Plus tard, J.-L. Brunaux et P. Méniel décrivent deux squelettes de bovins découverts à Gournay-surAronde (Oise) dans un puits rebouché au cours de la première moitié du $\mathrm{II}^{\circ} \mathrm{s}$. de notre ère (Brunaux, Méniel, 1983, p. 17). L'écart de $25 \mathrm{~cm}$ entre les moyennes des hauteurs au garrot et la variation des proportions des différents segments osseux incitent les auteurs à émettre l'hypothèse «qu'après la Conquête apparaît une nouvelle race, beaucoup plus grande, et dont le rendement en viande était bien supérieur à celui de la race indigène, non seulement à cause de sa hautcur plus élevée, mais aussi à cause de proportions différentes des masses musculaires " (ibid., p. 19). Les données disponibles au début des années 1980 montrent que plusieurs cas de figures sont possibles selon les sites : soit les deux types de bovins coexistent, soit seuls les grands sont présents, soit les animaux possèdent une taille intermédiaire (Bruneaux, Méniel, 1983, p. 19). Ainsi, P. Méniel, dans ses divers travaux, envisage l'importation de bovins romains sans toutefois rejeter la possibilité de l'amélioration du cheptel indigène grâce à l'importation d'un savoir-faire différent et au croisement des bovins indigènes avec les animaux importés. Il rejoint $A$. von den Driesch qui pense que « cette augmentation de la taille des boufs pendant les premières décennies de l'occupation romaine dans les régions nord des Alpes, était le résultat d'hybridation des vaches celtiques ou locales avec de grands taureaux italiques, introduits dans les provinces. Plus tard, alors que la romanisation était achevée et que l'économie romaine, avec les "villae rusticae", avait élé adoptée, on élevait, dans les régions occupées, des bœufs de grande taille. L'amélioration de la race bovine s'est réalisée par sélection, jointe à une bonne nourriture. " (Driesch, 1992, p. 120). Dans les mêmes années mais à l'autre extrémité de la France, T. Poulain-Josien publie les résultats de son étude sur les ossements animaux découverts dans la villa de Montmaurin, Haute-Garonne (Fouet dir., 1983). Les deux types de bovins coexistent dans la villa et l'auteur suggère une utilisation différente pour chacun d'eux : les individus de la petite "race " auraient été destinés à la consommation directe (lait et viande) et ceux de la grande « race " plutôt pour le travail (trait et portage). Cette proposition sera reprise par F. AudoinRouzeau qui se demande, à titre d'hypothèse, "s'il n'y a pas corrélation partielle entre la force de ces bêtes et la faible inventivité dont témoignent en contraste les Romains en matière de harnachement ou d'attelage (cette notion d'équipement médiocre est à présent souvent combattue comme une idée reçue et erronée par des historiens de l'Antiquité) " ${ }^{5}$ (Audoin-Rouzeau, 1997a, p. 31). Par ailleurs, cette même archéozoologue, lors de son essai de synthèse à l'échelle de l'Europe, reprend l'hypothèse de l'importation d'animaux qu'elle privilégie à celle de l'importation du savoir-faire, et associe la pénétration du bétail romain dans les différentes provinces de l'Empire à l'éloignement de celles-ci par rapport à l'Italie (Audoin-Rouzeau, 1991, p. 5). S. Lepetz montre à l'aide des résultats de ses travaux en France du Nord (Lepetz, 1995a, 1995b, 1996) que le remplacement des bovins indigènes par les bovins de grande taille est rapide, et qu'il s'agit d'une " rupture nette avec les époques précédentes. [...] Dans le cas d'une amélioration du cheptel local, des boufs de stature intermédiaire se rencontreraient dans de nombreux sites, or ce n'est pas le cas. " (Lepetz, 1996, p. 317 et fig. 2). Pour cet auteur, qui toutefois ne place pas la source écrite dans son contexte, notamment chronologique, la morphologie des bovins telle que l'on peut l'imaginer d'après les os retrouvés correspond à la description faite par Columelle (De l'agriculture, VI, II) : « Les bovins, dès lors présents dans le nord de la Gaule, répondent à tous ces critères, ce qui peut résulter de leur origine romaine " (Lepetz, 1996, p. 319). Les derniers travaux sur ce sujet confortent l'hypothèse de l'importation, qui débuterait avant même la conquête, fondée sur deux arguments principaux : d'une part, "l'apparition d'un effort sélectif sur les boufs et les taureaux par un régime alimentaire spécifique, grands animaux trop différents des formes indigènes pour en être directement issus, et qui vont les supplanter au début de notre ère, et une amélioration assez discrète des formes indigènes [...] » ct, d'autre part, « le fait que ces grands animaux apparaissent sur des sites ayant livré des amphores italiques en nombre significati-

5. F. Audoin-Roureau cite le travail de G. Raepsaet publié en 1995. 
vement plus élevé que la moyenne locale n'a donc rien de fortuit " (Horard-Herbin et al., 2000, p. 198 et 203). Pourtant, à ce jour, aucune synthèse archéologique effectuée en Italie n'a apporté la preuve que des grands bovins, ostéologiquement reconnus comme tels, vivaient dans la péninsule, et n'a permis de faire le lien avec ceux de Gaule romaine (cf. interprétation zootechnique, p. 291-297).

Le phénomène inverse, aussi complexe à cerner que l'accroissement de la corpulence des bovins, est celui de leur diminution durant le haut Moyen Âge. F. AudoinRouzeau, par exemple, explique que "surtout objets d'importation, ils [les grands bovins] disparaissent sans laisser de traces quand s'efface la présence romaine. [...] Le cheptel bovin conserve simplement son niveau de l'âge du Fer, une fois disparus les troupeaux importés qui venaient se juxtaposer aux bêtes indigènes sans que le mode d'élevage de celles-ci ne s'en soit trouvé durablement modifié " (Audoin-Rouzeau, 1991, p. 8). Diverses hypothèses ont été proposées pour expliquer ce fait: modification des choix zootechniques d'élevage, difficulté de nourrissage du bétail durant l'hiver, gestion différente de la viande dans les petites unités d'exploitation, développement des techniques agricoles au détriment de celles de l'élevage... (Driesch, 1992, p. 122 ; Audoin-Rouzeau, 1997a, p. 31). Cette dernière suggestion met en avant une concurrence entre, d'une part, l'élevage et, d'autre part, la poussée démographique, l'extension des terres céréalières, et donc le rétrécissement des surfaces de pâturage. Les animaux sont relégués sur les friches incultes et les champs ne sont plus enrichis par la fumure (Audoin-Rouzeau, 1991, p. 12). À l'inverse, à partir du XIV“s., la chute démographique et la rareté de la main-d'ouvre libèrent à nouveau des espaces, auparavant voués à l'agriculture, pour les troupeaux ; un élevage spécialisé et spéculatif se met alors en place. Ia corpulence du cheptel s'accroît à nouveau. On assiste à "la remontée ostéométrique dès le bas Moyen Âge avant que ne se fassent sentir les eflets de l'essor agronomique des Temps modernes " (AudoinRouzeau, 1991, p. 9 et 1995, p. 284). Par la suite, cet auteur abandonne cette vision : "Après dix siècles d'un bétail aux statures presque immobiles et d'un élevage médiéval soit impuissant à les modifier, soit indifférent à cette forme de rentabilisation, exigeante en soins, en nourriture et en vigilance sélective, les ćvolutions morphologiques des animaux aux Temps modernes apparais- sent une véritable nouveauté. L'homme ne se contente plus de garder, de nourrir et d'exploiter l'animal domestique, il contrôle à présent sa reproduction. L'idée de la sélection s'impose, et les premières notions de "races" vont apparaître. Mais "nouveauté" n'est peut-être pas cependant le terme adéquat : les éleveurs romains avaient en leur temps porté à un très haut degré les effets d'un tel élevage sélectif " (Audoin-Rouzeau, 1997b, p. 483).

\section{DÉFINITIONS, MATÉRIEL ET MÉTHODE}

Dans tous les travaux précédemment cités, la définition exacte des notions évoquées manque. Sur quels critères objectifs se reconnait le petit ou le grand bouf ? Aucune définition ostéomorphologique ou ostéométrique au sens strict n'a jamais été donnée ${ }^{6}$. Depuis fort longtemps, notre pratique quotidienne de l'archéozoologie nous conduit à étudier des lots de faune dans lesquels les restes osseux de bovins sont peu nombreux. Il est alors délicat de savoir dans l'absolu s'ils sont " petits " ou "grands ". Bien souvent, ils paraissent avoir appartenu à des individus de corpulence "moyenne ". C'est, par exemple, le cas à Argentomagus (Saint-Marcel, Indre) pour les os longs, en particulier les métapodes, de bovins issus de niveaux archéologiques datés du milieu du $\mathrm{I}^{\mathrm{ir}} \mathrm{s}$. de notre ère (Rodet-Belarbi, 1989).

La corpulence, ou format, d'un animal s'inscrit dans les trois dimensions de l'espace (fig. 2) : la stature, qui correspond à la hauteur de l'animal dans un axe vertical, la longueur qui se développe selon un axe horizontal, et la largeur perçue suivant un axe perpendiculaire au plan de symétrie de l'animal. La corpulence résulte de l'apparence volumique de l'animal, dessinée par l'enveloppe charnelle composée de tissus mous et soutenue par une charpente interne, le squelette, par des organes durs, les os. À l'heure actuelle, la corpulence d'un individu est liéc à son appartenance à une race. Elle est fixée comme gabarit par des standards élaborés par l'homme, mais qui peuvent varier au gré des modes ou des réorientations économiques. C'est pourquoi, nous réservons le terme

6. F. Audoin-Rouzcau montre qu’il y a " une séparation franche entre un bétail indigène variant en moyenne de $105 \mathrm{~cm}$ a $115-120 \mathrm{~cm}$, et un bétail importé variant de $120 \mathrm{~cm}$ à $135-140 \mathrm{~cm}$ " (Audoin-Rouzeau, 1991, p. 5). S. Lepetz dans sa thèse indique que " les individus dont la taille se situe contre $1 \mathrm{~m}$ et $1,20 \mathrm{~m}$ sont des petits boufs de type gaulois " (Lepet\%, 1995a, p. 79). 


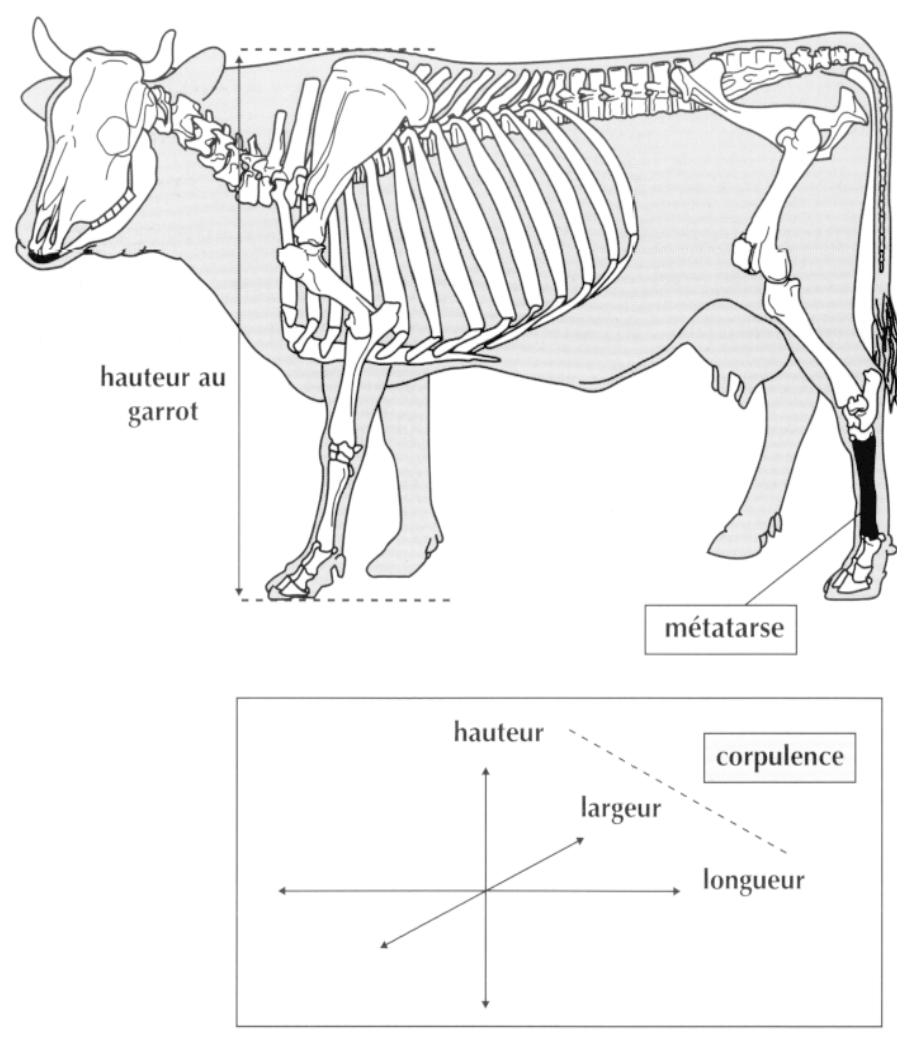

Fig. 2 - Corpulence et squelelte d'un bovin (DAO M. Coutureau et V. Forest, INRAP, d'après Barone, 1976).

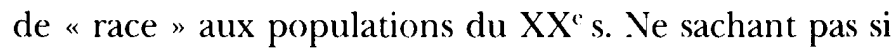
dans les périodes anciennes de tels choix existaient - c'est d'ailleurs un des axes d'investigation de l'archéozoologie -, nous préférons parler de "morphotype " pour définir des groupes d'individus qui partagent certains traits communs.

Comment appréhender cette corpulence? Il est possible de se référer à celles d'animaux actuels par le calcul d'une hauteur au garrot. Elle s'obtient par conversion de la grande longueur (GL) d'un os à l'aide d'un coefficient multiplicateur ${ }^{7}$. Pour le métatarse, celui-ci diffère suivant le sexe de l'animal, femelle, mâle entier, mâle castré. Préalablement au calcul, il faut donc

7. L’imprécision de cette estimation n'est plus à démontrer (Driesch, Boessneck, 1974 ; Chaix, 1980 ; Brunaux, Méniel, 1983 ; Forest, 1998b). Trois points principaux en sont responsables: 1) les coefficients diffèrent d'un auteur à l'autre pour un même os et il est donc impératif de comparer des résultats obtenus avec les mêmes coefficients; 2) la hauteur au garrot diffère selon les os emplovés pour son calcul, la variation pourant atteindre 10 à $15 \mathrm{~cm}$ pour un même individu: 3) d’après son équation de calcul, la hauteur au garrot est le produit d'une grande longueur d'os multipliée par un coefficient, seule la longueur des os est explorée et non leurs largeurs. procéder au sexage de l'animal originel à partir de l'os. Il se réalise classiquement par lecture d'un nuage de points obtenu à partir de deux variables, la grande longueur (GL) et la largeur minimale de la diaphyse (SD), en s'appuyant sur la différence théorique de proportions entre les métapodes (métacarpes et métatarses) de femelles - courts et fins -, de mâles - courts et larges -, de mâles castrés - longs et fins (voir par exemple, Méniel, Chaix, 1996, p. 33 et 36).

Or, dans une remarquable étude biologique complète et appliquée à l'archéozoologie, portant sur les métapodes des bovins de la race charolaise actuelle, C. Guintard (1996) a montré que le sexage des animaux par l'intermédiaire des métapodes ne peut être envisagé que si, au préalable, quelques vérifications sont effectuées : taille minimale du lot d'os analysés, étude de la variabilité au sein du lot... Il n'est donc pas possible de se contenter de la simple lecture d'un nuage de points évoquée précédemment. Cette constatation est corroborée par l'étude récente de $L$. Bartosiewicz, W. Van Neer et A. Lentacker (1997) sur les métapodes et les phalanges de boufs roumains actuels. Ces mâles castrés tardivement ont livré des métapodes de même longueur que ceux des taureaux. Cet exemple concret fournit un modèle biologique allant à l'encontre de l'affirmation selon laquelle les métapodes de bœufs sont toujours plus longs que ceux de taureaux. Il répond à une interrogation que nous avions formulée lors d'une réflexion sur les effets de la castration suivant l'âge auquel elle est effectuée, et suivant la technique opératoire adoptée (Forest, 1997, p. 954). L'estimation de la hauteur au garrot est, à notre sens, trop entachée d'incertitudes pour servir à une analyse précise des variations de corpulence chez les bovins. De plus, son calcul nécessitant des os entiers, elle réduit fortement le champ d'observation, puisque sur les sites archéologiques les séries ostéométriques les plus nombreuses sont issues d'os fragmentés, autrement dit, sont composées de mesures de largeurs. Or C. Guintard (1996) a démontré qu'au sein d'une race, dans l'acceptation de sa définition actuelle, quel que soit le sexe de l'animal, la longueur et la largeur des métapodes n'étaient pas étroitement corrélées ; la longueur de l'os est fortement corrélée à la hauteur au garrot tandis que la largeur n'est que partiellement corrélée à celle-ci mais est nettement liée à la corpulence, c'est-à-dire au volume global de l'animal. 
Les interrogations méthodologiques apparues lors de nos divers travaux, que sont venus étayer les résultats des études biologiques mentionnées ci-dessus, nous ont incités à reprendre le problème de la variation de la corpulence des bovins en nous fondant seulement sur les mesures brutes, prises selon les standards publiés par A. von den Driesch (1976). Cela nous permet de prendre en compte à la fois la longueur et la largeur de l'os, et d'explorer deux aspects de la variation de la corpulence de l'animal: sa hauteur et son volume. Notre enquête a commencé par examiner la question de l'existence du " grand bœuf » en Gaule romaine et, en conséquence, de l'importation ou non d'un "grand bœuf " par les Romains. Pour ce faire, nous avons réuni pour la Gaule le plus grand nombre possible de données métriques disponibles sur le métatarse qui est l'un des os longs les plus fréquemment trouvés sur les sites archéologiques (Forest, Rodet-Belarbi, 1997, 1998). Afin d'éviter une trop grande interférence du sexe sur les valeurs absolues mesurées (Guintard, 1996, p. 71), le métatarse a été préféré à son homologue antérieur, le métacarpe, qui enregistre plus fortement les différences dues au sexe de l'animal, car le taureau diffère de la vache surtout par un développement de l'avant-train auquel appartient le métacarpe. Dans la continuité de cette démarche, nous avons élargi notre travail à la période médiévale, en nous limitant à la France méridionale. Étant donné la plus grande rareté des données disponibles, nous avons choisi d'étudier outre le métatarse d'autres os et, pour chacun, les dimensions les plus couramment mesurées ${ }^{8}$. Cela nous a permis de suivre l'évolution des différents segments osseux entre eux. Les résultats de cette synthèse ont été présentés en 1998 lors des Journées scientifiques L'homme et l'animal dans les sociétés méditerranéennes à Perpignan (Forest, Rodet-Belarbi, 2000) ".

8. Scapula (SIC), humérus (GL, Bd), radius (GL, Bp), métacarpe (Bp et Bd), fémur (DC), tibia (GL, Bd), talus (GL, Bd) et calcanéus (GL).

9. Depuis, une exploration a été lancée sur les périodes du Néolithique moyen, du Néolithique final et du Chalcolithique dans le sud de la France dont les résultats ont été présentés lors des IV" rencontres de Préhistoire récente (Nîmes, Gard), octobre 2000, cf. I. Carrère, V. Forest, à paraître. Elle enrichit notre rétlexion diachronique exposée lors du séminaire de recherche "Mouvements et déplacements de populations animales en Méditerranée au cours de l'Holocène " (Lattes, Hérault, sept. 2000), cf. Carrère el al., à paraître.
Les limites chronologiques choisies pour les deux premières études sont très vite apparues «stérilisantes". Une vision diachronique longue des variations des dimensions osseuses s'est imposée, car les événements d'une période peuvent apporter des éléments servant à la compréhension des événements d'une autre phase chronologique. Puisqu'au cours de notre travail sur la France méridionale médiévale et moderne le métatarse s'est avéré être un témoin fiable des modifications générales des autres os des membres, il a été gardé pour cette présentation de synthèse.

Afin d'avoir la vision diachronique nécessaire à une meilleure lecture des événements biologiques et zootechniques qui ont conduit aux modifications physiques des bovins, toutes les données métriques collectées pour le métatarse ont été disposées dans les tableaux III, IV et V. L'étendue de la variation des valeurs des mesures, en millimètres, est divisée en classes. L'effectif d'os possédant cette valeur est affiché pour chacune d'elles. Cette standardisation permet de visualiser les variations des trois mesures (GL : grande longueur; $\mathrm{Bp}$ : largeur proximale ; $\mathrm{Bd}$ : largeur distale). Les valeurs, regroupées en quatre ensembles de cinq ou six classes chacun, désignent les métatarses par les qualificatifs " petit ", " moyen ", " grand " et " très grand " (Forest, RodetBelarbi, 1998, p. 1 034). À titre comparatif, l'estimation des hauteurs au garrot, en centimètres (Matolcsi, 1970), est indiquée en regard des classes dans le tableau III, qui concerne la grande longueur (GL). Les deux hypothèses extrêmes, taureaux (coefficient : 0,562 ) et vaches (coefficient : 0,528 ) sont proposées.

Les phases chronologiques proposées ci-dessous ont été déterminées par les datations des contextes archéologiques d'où sont issus les ossements, tout en essayant d'affiner au mieux les périodes « charnières ». Le point de départ de ce travail se situe au ${ }^{\mathrm{Ir}} \mathrm{s}$. avant notre ère, car il nous a paru intéressant de conserver les données de niveaux archéologiques de cette période quand elles proviennent de sites importants tels que Villeneuve-SaintGermain (Aisne) ${ }^{10}$, afin de faire le lien avec la période gallo-romaine pour laquelle les phases chronologiques sont les suivantes :

10. Les données métriques recueillies à Villeneuve-Saint-Germain semblent résumer à elles seules les tailles des bovins en France du Nord, tant par l'étendue de la variation des dimensions que par la moyenne des hauteurs au garrot (d'après fig. 7, cf. Méniel, 1987, p. 162). 


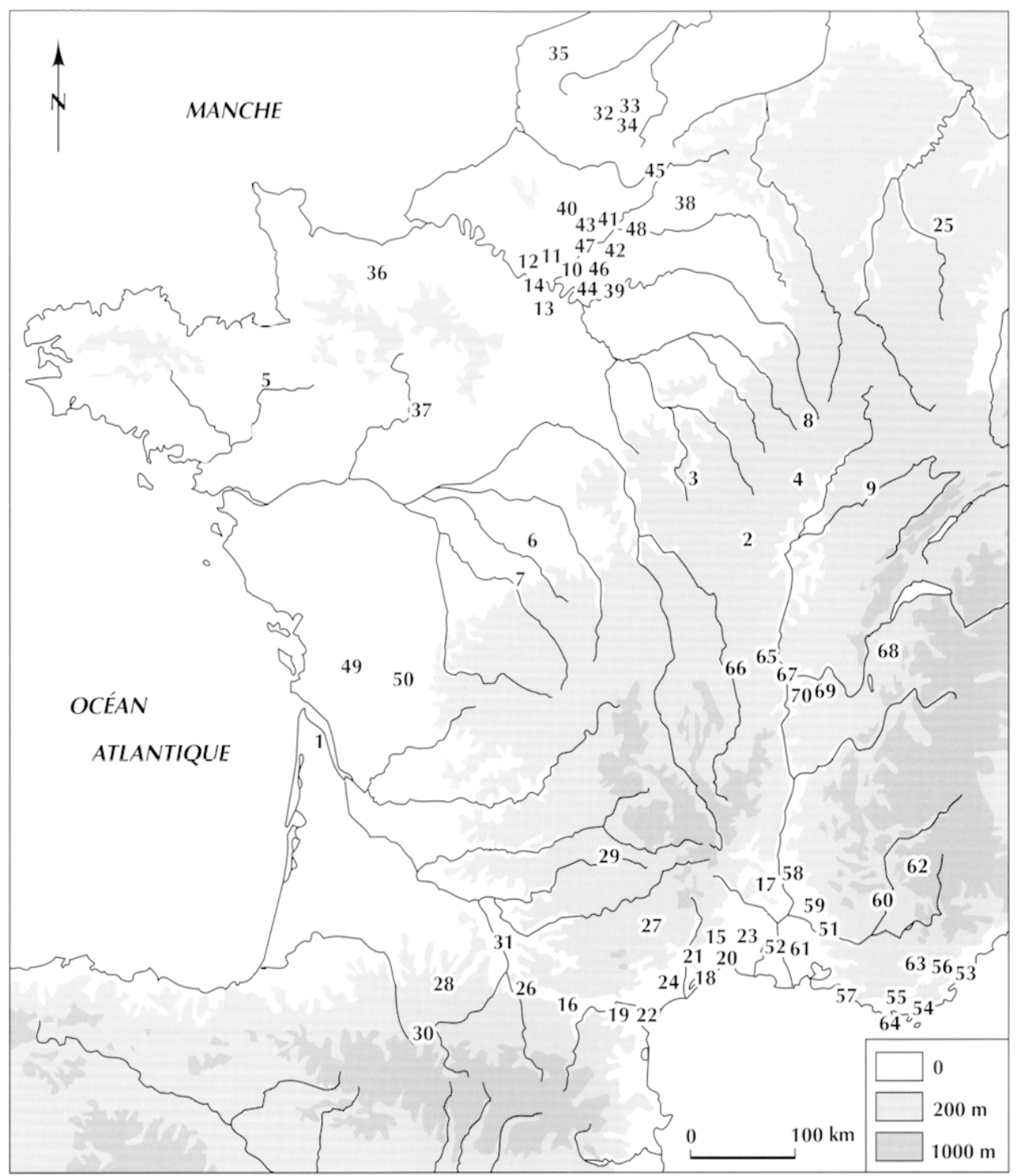

Fig. 3 - Localisation géographique des sites gaulois et gallo-romains (DAO, V. Forest, INRAP, d'après fonds de carte (C) M. Feugère, M. Py, CNRS, 1993).

AQtTTAINE: 1, Saint-Germain-d Lsteuil (Gironde).

BolRcolive: 2, Autun (Sâ̂ne-et-Loire) ; 3, Foissy-lès-Vézelay) (Yonne) ; 4, Mirebeau-sur-Bèze (Côte-d'Or).

BRl:TAGive: 5, Rennes (Ille-el-Vilaine).

(W.NTRl: : 6, Leoroux (Indre) ; 7, Saint-Marcel (Indre).

(HAMPAtiNe: 8 , Langres (Haute-Marne).

FRANCHE-CoMTE : 9, Besangon (Doubs).

IIlE-1)k-FRANCE: : 10, Beaumont-sur-Oise (Val-d'Oise) ; 11, Epiais-Rhus (Val-d'Oise); 12, Genainville (Val-d'Oise); 13, Meulan (Yvelines) ; 14, Saint-Denis (Seine-Saint-Denis).

LANGLEDOC-RolssiLLON : 15, Ambrussum/Villetelle (Hérault) ; 16, Bram (Aude) ; 17, Gaujac (Gard) ; 18, Loupian (Hérault) ; 19, Luc-surOrbieu (Aude) ; 20, Lunel-Viel (Héraull); 21, Monlagnac (Hérault);22, Narbonne (Aude); 23, Nîmes (Card) ; 24, Puissalicon (Hérault). LoRRAINE: 25, Bliesbruck (Moselle).

MIII-PYRENELS: 26, Auterive (Haute-Garonne) ; 27, L'Hospitalet-du-Larzac (Aveyron) ; 28, Montmaurin (Haule-Caronne) ; 29, Rodez (Aveyron) ; 30, Saint-Bertrand-de-Comminges (Haule-Garonne) ; 31, Toulouse (Haute-Garonne).

NoR) : 32, Arras (Pas-de-Calais) ; 33, Hamblain-les-Prés (Pas-de-Calais) ; 34, Monchy-le-Preux (Pas-de-Calais) ; 35, Zouafques (Pas-de-Calais). NORMANIIE: : 36, Vieux (Caluados).

PArS IDE LA LoIRE: 37, Le Mans (Sarthe).

Pl(atrdIt: : 38, Athies-sous-Laon (Aisne) ; 39, Baron (Oise); 40, Beauvais (Oise); 41, Estrées-Saint-Denis (Oise) ; 42, Longueil-Sainte-Marie (Oise) ; 43, Montmartin (Oise) ; 44, Plailly (Oise) ; 45, Saint-Quentin (Aisne) ; 46, Senlis (Oise) ; 47, Verneuil-en-Halatte (Oise) ;

48, Villeneuve-Saint-Germain (Aisne).

Portol-ChaRlavts: : 49, Aulnay (Charente-Maritime); 50 ), Cabariot (Charente).

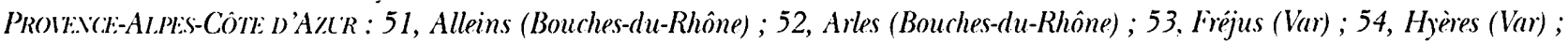

55, La Garde (Var) ; 56, Les Arcs (Var) ; 57, Marseille (Bouches-du-Rhône) ; 58, Mondragon (Vaucluse) ; 59, Pernes-les-Fontaines (Vaucluse) ; 60, Peyruis (Alpes-de-Haute-Provence) ; 61, Saint-Rém)-de-Provence (Bouches-du-Rhône) ; 62, Salignac (Alpes-de-Haute-Provence) ; 63, Taradeau (Var) ; 64, Toulon (Var).

RHÔN:-AltPS: : 65, Chess) (Rhône) ; 66, Feurs (Loire) ; 67, Lyon (Rhône) ; 68, Chanaz Porlout (Sazoie) ; 69, Saint-Romain-de-Jalionas (Isère) ; 70, Simandres (Rhône). 
Tabl. I - Liste des sites gaulois et gallo-romains mentionnés figure 3 (la datation correspond à la chronologie globale du site).

\begin{tabular}{|c|c|c|c|c|c|}
\hline $\mathbf{N}^{\circ}$ & Nom des villes & Nom des sites & Datation & Étude de la faune & Références bibliographiques \\
\hline \multicolumn{6}{|l|}{ Aquitaine } \\
\hline 1 & Saint-Germain-d'Esteuil (Gironde) & Agglomération & 300 av. J.-C.-300 apr. J.-C. & 1. Rodet-Belarbi & Étude en cours (dir. P. Garmy) \\
\hline \multicolumn{6}{|l|}{ Bourgogne } \\
\hline \multirow[t]{2}{*}{2} & \multirow[t]{2}{*}{ Autun (Saône-et-Loire) } & Institution Saint-Lazare & $50-80$ & I. Rodet-Belarbi & Rodet-Belarbi, 1993a \\
\hline & & Lycée militaire & $50-400$ & I. Rodet-Belarbi & Chardron-Picault et al., 1999 \\
\hline 3 & Foissy-lès-Vézelay (Yonne) & Fontaines-Salées & $300-400$ & T. Poulain-Josien & Poulain-Josien, 1965-1966 \\
\hline 4 & Mirebeau-sur-Bèze (Côte-d'Or) & Camp militaire & 75-100 & S. Lepetz & Goguey et al., 1995 \\
\hline \multicolumn{6}{|l|}{ Bretagne } \\
\hline 5 & Rennes (Ille-et-Vilaine) & Rue Île-Saint-Malo & $50-300$ & S. Krausz & Information orale \\
\hline \multicolumn{6}{|l|}{ Centre } \\
\hline 6 & Levroux (Indre) & Terrains Lacotte/Lambert & 100 av. J.-C.-15 apr. J.-C. & S. Krausz & Krausz, 1985 \\
\hline \multirow[t]{5}{*}{7} & \multirow[t]{5}{*}{ Saint-Marcel (Indre) } & Les temples & 25 av. J.-C.-125 & L. Chaix ; I. Rodet-Belarbi & Allain et al., 1981 ; Rodet-Belarbi, 1989 \\
\hline & & La fontaine & $0-65$ & 1. Rodet-Belarbi & Rodet-Belarbi, 1989 \\
\hline & & La voie Est-Ouest & 25 av. J.-C.- -420 & 1. Rodet-Belarbi & Dumasy et al., 1996 \\
\hline & & Parcelle Petit & 25 av. J.-C.-20 & T. Poulain-Josien ; Rodet-Belarbi & Allain et al., 1966 ; Rodet-Belarbi, 1989 \\
\hline & & Parcelle Brançon & 25 av. J.-C.-100 & 1. Rodet-Belarbi & Rodet-Belarbi, 1989 \\
\hline \multicolumn{6}{|l|}{ Champagne } \\
\hline 8 & Langres (Haute-Marne) & Marché couvert & $50-100$ & 1. Rodet-Belarbi & Barral et al., 1993 \\
\hline \multicolumn{6}{|c|}{ Franche-Comté } \\
\hline 9 & Besançon (Doubs) & Parking de la Mairie & 120 av. J.-C.- 120 & P. Méniel & Guilho et al., 1992 \\
\hline \multicolumn{6}{|l|}{ île-de-France } \\
\hline 10 & Beaumont-sur-Oise (Val-d'Oise) & La Blanche-Voye & $0-500$ & S. Lepetz & Lepetz, 1995a \\
\hline 11 & Épiais-Rhus (Val-d'Oise) & Villa d'Éros & $0-50$ & G. Marchand & Marchand, 1979 \\
\hline 12 & Genainville (Val-d'Oise) & Temple gallo-romain & 200-300 & T. Poulain-Josien & Mitard et al., 1993 \\
\hline 13 & Meulan/Les Muraux (Yvelines) & île-Belle & 30 av. J.-C.-150 & A.-G. Philippot ; I. Rodet-Bel. & Philippot, 1992 ; étude inédite \\
\hline 14 & Saint-Denis (Seine-Saint-Denis) & Aire 17 (F976) & $350-400$ & 1. Rodet-Belarbi & Rodet-Belarbi, 1998 \\
\hline \multicolumn{6}{|c|}{ Languedoc-Roussillon } \\
\hline 15 & AmbrussumVilletelle (Hérault) & Quartier du Sablas & 50 av. J.-C. -50 & P. Columeau & Columeau, 1985 ; Fiches, Columeau, 1989 \\
\hline 16 & Bram (Aude) & & $50-100$ & A. Gardeisen & Passelac, Gardeisen, 1995 \\
\hline 17 & Gaujac (Gard) & Oppidum Saint-Vincent & 100 av. J.-C.-200 & M. Leguilloux & Leguilloux, 1994 \\
\hline 18 & Loupian (Hérault) & Prés-Bas & $100-200$ & P. Columeau & Columeau, 1985 \\
\hline 19 & Luc-sur-Orbieu (Aude) & Villa du Jonquas & 10 av. J.-C. -25 & Y. Lignereux & Étude inédite \\
\hline 20 & Lunel-Viel (Hérault) & Bâtiment A & $200-350$ & V. Forest & Favory et al., 1993 \\
\hline 21 & Montagnac (Hérault) & Villa de Lieussac & $230-260$ & V. Forest & Mauné, Forest, 1995 \\
\hline 22 & Narbonne (Aude) & Hôtel-Dieu & $400-500$ & A. Gardesein & Ginouvez, Gardeisen, 1996 \\
\hline \multirow[t]{2}{*}{23} & \multirow[t]{2}{*}{ Nîmes (Gard) } & Saint-André-de-Codols & $100-500$ & A. Gardeisen & Pomarèdes, Gardeisen, 1994 \\
\hline & & ZAC des Halles & 100 av. J.-C. -450 & A. Gardeisen & Monteil, Gardeisen, 1993 \\
\hline 24 & Puissalicon (Hérault) & Les Jurièires-Basses & $400-600$ & V. Forest & Mauné, Forest, 1997 \\
\hline \multicolumn{6}{|l|}{ Lorraine } \\
\hline 25 & Bliesbruck (Moselle) & Reinheim, fosses, puits & $0-200$ & P. Méniel & Méniel, 1993 \\
\hline \multicolumn{6}{|c|}{ Midi-Pyrénées } \\
\hline 26 & Auterive (Haute-Garonne) & Saint-Orens & 50 av. J.-C. -70 & T. Poulain-Josien & Latour, Poulain-Josien, 1970 \\
\hline 27 & L'Hospitalet-du-Larzac :Aveyron) & La Vayssière/A75 & 20 av. J.-C.-120 & I. Rodet-Belarbi & Ruiné-Lacabe, 1992 \\
\hline 28 & Montmaurin (Haute-Garonne) & Puits funéraire & $300-400$ & T. Poulain-Josien & Fouet, Poulain-Josien, 1958 \\
\hline \multirow[t]{2}{*}{29} & \multirow[t]{2}{*}{ Rodez (Aveyron) } & Bld d'Estourmel & $200-300$ & 1. Rodet-Belarbi & Martin, Gangloff, 1994 \\
\hline & & Rue Combarel & $50-150$ & Y. Lignereux & Lignereux et al., 1994 \\
\hline \multirow[t]{2}{*}{30} & Saint-Bertrand-de-Comminges (Hte-G.) & Macellum & 40 av. J.-C.-15 & N. My & My, 1993 \\
\hline & & Place du Portique & $0-100$ & S. Padiolleau & Thèse en cours \\
\hline 31 & Toulouse (Haute-Garonne) & Donjon-Capitole & $400-700$ & 1. Rodet-Belarbi & Catalo et al., 1996 \\
\hline & & Extension Préfecture & $150-1600$ & 1. Rodet-Belarbi & Catalo et al., 1995a \\
\hline & & Parking Esquirol & $60-1500$ & 1. Rodet-Belarbi & Arramond et al., 1993 \\
\hline & & Paul Feuga & $400-600$ & 1. Rodet-Belarbi & Peyre et al., 1994 \\
\hline & & Rectorat & $350-600$ & 1. Rodet-Belarbi & Cazes et al., 1989 \\
\hline
\end{tabular}


Tabl. I - Liste des sites gaulois et gallo-romains mentionnés figure 3 (suite).

\begin{tabular}{|c|c|c|c|c|c|}
\hline $\mathrm{N}^{\circ}$ & Nom des villes & Nom des sites & Datation & Étude de la faune & Références bibliographiques \\
\hline \multicolumn{6}{|l|}{ Nord } \\
\hline \multirow[t]{5}{*}{32} & \multirow[t]{5}{*}{ Arras (Pas-de-Calais) } & Fosses F81/F82 & $0-25$ & S. Lepetz & Lepetz, 1995a \\
\hline & & Baudimont, puits Г07 & $70-100$ & S. Lepetz & Lepetz, 1995a \\
\hline & & Dépotoir civil A78 & $300-400$ & S. Lepetz & Lepetz, 1995a \\
\hline & & Dépotoir militaire D87 & 375425 & S. Lepetz & Lepetz, 1995a \\
\hline & & Villa du Mont Saint-Vaast & $25-75$ & S. Lepetz & Lepetz, 1995a \\
\hline 33 & Hamblain-les-Prés (Pas-de-Calais) & Les Bonnettes & $25-75$ & S. Lepetz & Lepetz, 1995a \\
\hline 34 & Monchy-le-Preux (Pas-de-Calais) & Villa & $375-425$ & S. Lepetz & Lepetz, 1995a \\
\hline 35 & Zouafques (Pas-de-Calais) & Wolphus & $275-325$ & S. Lepetz & Lepetz, 1995a \\
\hline \multicolumn{6}{|l|}{ Normandie } \\
\hline 36 & Vieux (Calvados) & & $75-400$ & S. Lepetz & Lepetz, 1995a \\
\hline \multicolumn{6}{|c|}{ Pays de la Loire } \\
\hline \multirow[t]{2}{*}{37} & Le Mans (Sarthe) & Étoile-Jacobins & $0-100$ & I. Rodet-Belarbi & Pouli et al., 1989 \\
\hline & & Claude Chappe II & $0-50$ & 1. Rodet-Belarbi & Mercier, Rodet-Belarbi, 1989 \\
\hline \multicolumn{6}{|l|}{ Picardie } \\
\hline 38 & Athies-sous-Laon (Aisne) & Le Bois d'Empreville & $300-400$ & S. Lepetz & Lepetz, 1995a \\
\hline 39 & Baron (Oise) & Buisson-Saint-Cyr & 25 av. J.-C.-100 & S. Lepetz & Lepetz, 1995a \\
\hline 40 & Beauvais (Oise) & Hôtel-Dieu & $0-1900$ & S. Lepetz & Lepetz, 1995a \\
\hline 41 & Estrées-Saint-Denis (Oise) & Le Moulin des Hayes & $0-100$ & S. Lepetz & Lepetz, 1995a \\
\hline \multirow[t]{2}{*}{42} & \multirow[t]{2}{*}{ Longueil-Sainte-Marie (Oise) } & Le Bois Harlé & $100-300$ & S. Lepetz & Lepetz, 1995a \\
\hline & & La Queue de Rivecourt & $100-300$ & S. Lepetz & Lepetz, 1995a \\
\hline 43 & Montmartin (Oise) & Le Moulin à Vent & $0-400$ & S. Lepetz & Lepetz, 1995a \\
\hline 44 & Plailly (Oise) & La Bute Grise & $0-400$ & S. Lepetz & Lepetz, 1995a \\
\hline 45 & Saint-Quentin (Aisne) & Hôtel-Dieu & $100-300$ & S. Lepetz & Lepetz, 1995a \\
\hline 46 & Senlis (Oise) & Impasse du Courtillet & $0-100$ & S. Lepetz & Lepetz, 1995a \\
\hline 47 & Verneuil-en-Halatte (Oise) & Le Bulfosse & $0-400$ & S. Lepetz & Lepetz, 1995a \\
\hline 48 & Villeneuve-Saint-Germain (Aisne) & & 90-30 av. J.-C. & G. Auxiette & Auxiette, 1994 \\
\hline \multicolumn{6}{|c|}{ Poitou-Charentes } \\
\hline 49 & Aulnay (Charente-Maritime) & Camp militaire & $20-30$ & Y. Lignereux, J. Peters & Lignereux, Peters, 1997a et b \\
\hline 50 & Cabariot (Charente) & Mortantambe & $50-100$ & A. Gardeisen & Toledo I Mur et al., 1998 \\
\hline \multicolumn{6}{|c|}{ Provence-Alpes-Côte d'Azur } \\
\hline 51 & Alleins (Bouches-du-Rhône) & Tamberlette & $100-200$ & 1. Rodet-Belarbi & Rodet-Belarbi, 1997 \\
\hline 52 & Arles (Bouches-du-Rhône) & Quartier de l'Esplanade & $400-425$ & M. Leguilloux & Congès et al., 1991 \\
\hline 53 & Fréjus (Var) & Les Aiguières & $0-200$ & P. Columeau & Columeau, 1985 \\
\hline 54 & Hyères (Var) & Olbia & $200-550$ & M. Leguilloux & Leguilloux, 1994 \\
\hline 55 & La Garde (Var) & Villa Saint-Michel & $100-400$ & P. Columeau & Columeau, 1985 \\
\hline 56 & Les Arcs (Var) & Villa des Laurons & $250-400$ & M. Leguilloux & Berato et al., 1990 \\
\hline \multirow[t]{2}{*}{57} & \multirow[t]{2}{*}{ Marseille (Bouches-du-Rhône) } & La Bourse & $400-1025$ & M. Leguilloux & Leguilloux, 1994 \\
\hline & & La Cathédrale & $400-1400$ & M. Leguilloux & Leguilloux, 1994 \\
\hline 58 & Mondragon (Vaucluse) & Les Brassières & 150 av. J.-C.-0 & V. Forest & Vermeule, Forest, 1997 \\
\hline 59 & Pernes-les-Fontaines (Vaucluse) & Labourage & $300-400$ & M. Leguilloux & Leguilloux, 1994 \\
\hline 60 & Peyruis (Alpes-de-Haute-Provence) & La Casine & $300-400$ & M. Leguilloux & Leguilloux, 1994 \\
\hline 61 & Saint-Rémy-de-Provence (B.-du-Rhône) & Glanum & $300-500$ & M. Leguilloux & Leguilloux, 1994 \\
\hline 62 & Salignac (Alpes-de-Haute-Provence) & La Vallée & $100-200$ & A. Gardeisen & Boiron, Gardeisen, 1993 \\
\hline 63 & Taradeau (Var) & L'Ormeau & $50-100$ & P. Columeau & Columeau, 1985 \\
\hline 64 & Toulon (Var) & îlot des Riaux & $125-250$ & M. I eguilloux & Leguilloux, 1994 \\
\hline \multicolumn{6}{|l|}{ Rhône-Alpes } \\
\hline 65 & Chessy (Rhône) & Colombier & $50-100$ & P. Columeau & Columeau, 1985 \\
\hline 66 & Feurs (Loire) & Habitat & 160-20 av. J.-C. & E. Vila & Vaginay et al., 1988 \\
\hline \multirow[t]{5}{*}{67} & \multirow[t]{5}{*}{ Lyon (Rhône) } & Place des Célestins & $250-900$ & V. Forest & Arlaud et al., 1993 \\
\hline & & Place des Terreaux & $200-1600$ & V. Forest & Arlaud, Forest, 1995 \\
\hline & & Place Widor & $0-100$ & P. Columeau, I. Rodet-Bel. & Villedieu, 1990 ; Béal, Rodet-Bel., 1997-1998 \\
\hline & & Saint-Jean, îlot Tramassac & $300-900$ & R.-M. Arbogast & Arlaud et al., 1994 \\
\hline & & Temple de Cybèle & 40-10 av. J.-C. & V. Forest & Étude en cours (dir. A. Desbat) \\
\hline 68 & Chanaz Portout (Savoie) & Portout, atelier de potiers & $400-500$ & C. Olive & Pernon et al., 1990 \\
\hline 69 & Saint-Romain-de-Jalionas (Isère) & Villa & $300-500$ & V. Forest & Royet, Forest, 1995 \\
\hline 70 & Simandres (Rhône) & La Plaine & $400-800$ & V. Forest & Bouvier, Forest, 1993 \\
\hline
\end{tabular}




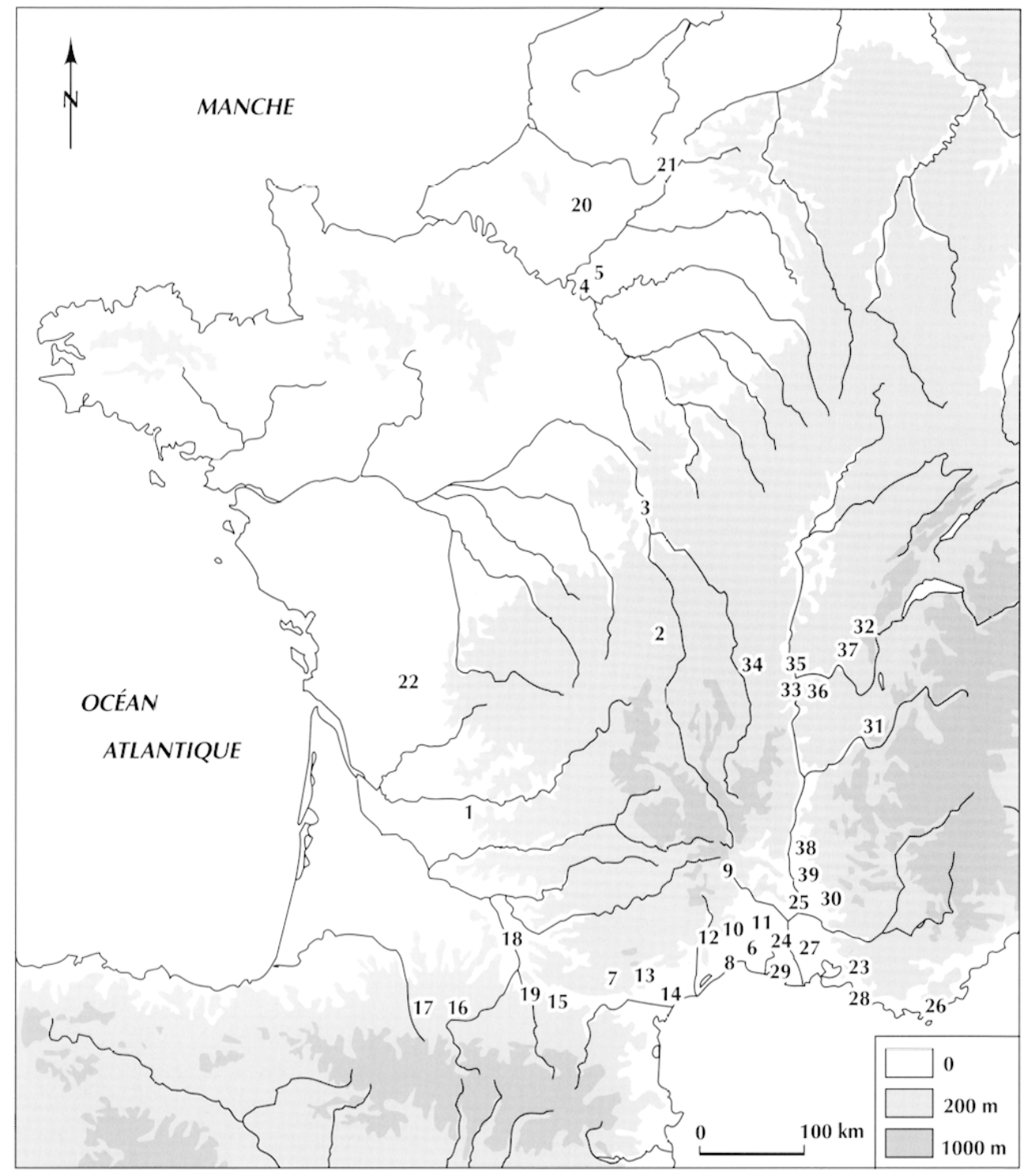

Fig. 4 - Localisation géographique des sites médiévaux et modernes (IDAO, V. Forest, INRAP, d'après fonds de carte (C) M. Feugère, M. P'), CNRS, 1993).

AQlITAINE: : 1, Saint-Avit-Sénieur (Dordogne).

AuviR(iNk: : 2, Aigueperse (Puy-de-I)ôme).

BotRcoogiv: : 3, La Charité-sur-Loire (Nièrre).

IItE-DE-FRAN(E: : 4, Paris ; 5, Saint-Denis (Seine-Saint-Denis).

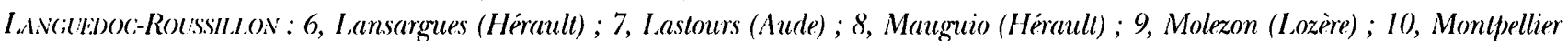
(Hérault) ; 11, Nîmes (Garard) ; 12, Plaissan (Hérault); 13, Quarante (Hérault) ; 14, Béziers, Saint-Jean-d'Aureilhan (Héraull) ;

15, Villeneuve-la-Comptal (Aude).

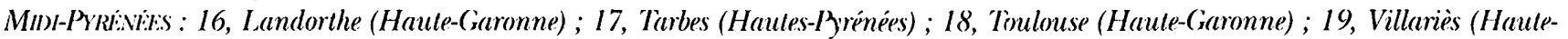
(iaronne).

PICARIE: : 20, Beauvais (Oise) ; 21, Hargicourt (Aisne).

POITOL-CHARENTES: 22, Villejoubert (Charente).

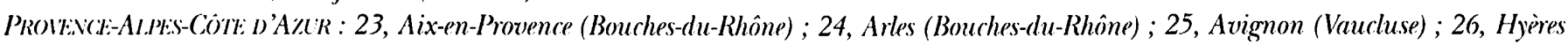
(Var) ; 27, Saint-Martin-de-Crau (Bouches-du-Rhône) ; 28, Marseille (Bouches-du-Rhône) ; 29, Saintes-Maries-de-la-Mer (Bouches-du-Rhône) ; 30), Vaison-la-Romaine (Vaucluse).

RHONN-ALPl:S : 31, Charavines (Isère) ; 32, Château-Gaillard (Ain) ; 33, Décines-Charpieu (Rhône) ; 34, Essertines-en-Châtelneuf (Loire) ; 35, Lyon (Rhône) ; 36, Meyzieu (Rhône) ; 37, Poncin (Ain) ; 38, Rochefort-en-Valdaine (I)rôme) ; 39, Saint-Paul-Trois-Châteaux (Drôme). 
Tabl. II - Liste des sites médiénaux el modernes mentionnés figure 4 (la datation correspond à la chronologie globale du site).

\begin{tabular}{|c|c|c|c|c|c|}
\hline & Nom des villes & Nom des sites & Datation & Étude de la faune & Références bibliographiques \\
\hline \multicolumn{6}{|c|}{ Aquitaine } \\
\hline 1 & Saint-Avit-Sénieur (Dordogne) & L'Abbaye & $1000-1200$ & A. Gauthier & Gautier, 1972 \\
\hline \multicolumn{6}{|c|}{ Auvergne } \\
\hline 2 & Aigueperse (Puy-de-Dôme) & Les Cérais & $700-1100$ & V. Forest & Alfonso, Forest, 1998 \\
\hline \multicolumn{6}{|c|}{ Bourgogne } \\
\hline 3 & La Charité-sur-Loire (Nièvre) & Le Monastère & $1000-1600$ & F. Audoin-Rouzeau & Audoin-Rouzeau, 1986 \\
\hline \multicolumn{6}{|c|}{ île-de-France } \\
\hline 4 & Paris & Jardins du Carrousel & $1500-1565$ & 1. Rodet-Belarbi & Van Ossel et al., 1991, 1998 \\
\hline 5 & Saint-Denis (Seine-Saint-Denis) & ? & $950-1200$ & C. Morel & Morel, 1985 \\
\hline \multicolumn{6}{|c|}{ Languedoc-Roussillon } \\
\hline 6 & Lansargues (Hérault) & Moulines & $700-1100$ & V. Forest & Martin, Forest, 1996 \\
\hline 7 & Lastours (Aude) & Cabaret & $1100-1225$ & V. Forest & Forest, 1992 ; Gardel et al., 1999 \\
\hline 8 & Mauguio (Hérault) & Aire Saint-Jacques & $800-1100$ & A. Gardeisen & Gardeisen, 1993 \\
\hline 9 & Molezon (Lozère) & Tour du Canourgue & $1250-1350$ & V. Forest & Étude inédite (Forest) \\
\hline \multirow[t]{3}{*}{10} & \multirow[t]{3}{*}{ Montpellier (Hérault) } & Faculté de Droit & $1200-1400$ & V. Forest & Ginouvez, Forest, 1997-1999 \\
\hline & & Faubourg de Nîmes & $1600-1800$ & V. Forest & Étude en cours (dir. C. Arlaud) \\
\hline & & L. Blanc/Pasteur & $1500-1600$ & I. Rodet-Belarbi & Bergeret et al., 1998 \\
\hline 11 & Nîmes (Gard) & ZAC des Carmes & $1375-1425$ & I. Rodet-Belarbi & Barberan et al., 1998 \\
\hline 12 & Plaissan (Hérault) & Les Termes & $500-700$ & V. Forest & Schneider, Forest, 1997 \\
\hline 13 & Quarante (Hérault) & Soulomiac & $500-700$ & V. Forest & Bermond, Forest, 1996 \\
\hline 14 & Béziers, Saint-Jean-d'Aureilhan (Hérault) & ZAC Montimaran & $1000-1200$ & I. Rodet-Belarbi & Jandot et al., 1998-1999 \\
\hline 15 & Villeneuve-la-Comptal (Aude) & Laval-Basse & $1200-1400$ & V. Forest & Forest, 1992 \\
\hline \multicolumn{6}{|c|}{ Midi-Pyrénées } \\
\hline 16 & Landorthe (Haute-Garonne) & Le Castéra & $1250-1350$ & I. Rodet-Belarbi & Boudartchouk et al., 1995 \\
\hline 17 & Tarbes (Hautes-Pyrénées) & Place de Verdun & $1100-1600$ & I. Rodet-Belarbi & Rodet-Belarbi, 1993b \\
\hline \multirow[t]{6}{*}{18} & \multirow[t]{6}{*}{ Toulouse (Haute-Garonne) } & Donjon-Capitole & $400-1700$ & I. Rodet-Belarbi & Catalo et al., 1996 \\
\hline & & Extension Préfecture & $450-1600$ & I. Rodet-Belarbi & Catalo, Chiabrando et al., 1995 \\
\hline & & Hôtel d'Assézat & $1100-1600$ & I. Rodet-Belarbi & Catalo, Llech et al., 1995 \\
\hline & & Parking Esquirol & $400-1700$ & I. Rodet-Belarbi & Arramond et al., 1993 \\
\hline & & Place Saint-Étienne & $1500-1700$ & B. Personnaz & Personnaz, 1992 \\
\hline & & Saint-Jacques/Rectorat & $1400-1600$ & 1. Rodet-Belarbi & Cazes et al., 1989 \\
\hline 19 & Villariès (Haute-Garonne) & Notre-Dame de Pinel & $1500-1600$ & N. Billault & Billault, 1997 \\
\hline \multicolumn{6}{|c|}{ Picardie } \\
\hline 20 & Beauvais (Oise) & Hôtel-Dieu & $800-1900$ & S. Lepetz & Lepetz, 1991 \\
\hline 21 & Hargicourt (Aisne) & La Cologne & $1375-1425$ & P. Méniel & Méniel, 1989 \\
\hline \multicolumn{6}{|c|}{ Poitou-Charentes } \\
\hline 22 & Villejoubert (Charente) & Andone & $950-1028$ & A. Grenouilloux & Grenouilloux, 1989 \\
\hline \multicolumn{6}{|c|}{ Provence-Alpes-Côte d'Azur } \\
\hline 23 & Aix-en-Provence (Bouches-du-Rhône) & Les Magnans & $1300-1400$ & M. Leguilloux & Leguilloux, 1994 \\
\hline \multirow[t]{2}{*}{24} & Arles (Bouches-du-Rhône) & Augéry-de-Corrèges & $800-1000$ & & Gardeisen, 1993 \\
\hline & & Les Prêcheurs & $1300-1400$ & M. Leguilloux & Leguilloux, 1994 \\
\hline 25 & Avignon (Vaucluse) & L'Oratoire & $1300-1400$ & M. Leguilloux & Leguilloux, 1994 \\
\hline 26 & Hyères (Var) & Olbia & $525-550$ & M. Leguilloux & Leguilloux, 1994 \\
\hline 27 & Saint-Martin-de-Crau (B.-du-Rhône) & La Fourbine & $500-700$ & P. Columeau & Columeau, 1985 \\
\hline 28 & Marseille (Bouches-du-Rhône) & La Bourse & $525-1025$ & M. Leguilloux & Leguilloux, 1994 \\
\hline & & La Cathédrale & $1200-1400$ & M. Leguilloux & Leguilloux, 1994 \\
\hline 29 & Saintes-Maries-de-la-Mer (B.-du-Rhône) & Cabassole & $700-1000$ & V. Forest & Pascalini et al., à paraitre \\
\hline & & Les Combettes & $700-1000$ & V. Forest & Pascalini et al., à paraittre \\
\hline 30 & Vaison-la-Romaine (Vaucluse) & La Villasse & $900-1200$ & V. Forest & Étude inédite (Forest) \\
\hline & & & & & \\
\hline 31 & Charavines (Isère) & & $900-1100$ & C. Olive & Colardelle et al., 1993 \\
\hline 32 & Château-Gaillard (Ain) & Le Recourbe & $900-1100$ & V. Forest & Étude en cours (dir. G. Vicher, E. Boucharlat) \\
\hline 33 & Décines-Charpieu (Rhône) & Le Moléron & $900-1100$ & V. Forest & Forest, 1987 ; Bouvier et al., 1992 \\
\hline 34 & Essertines-en-Châtelneuf (Loire) & Le Château & $1100-1300$ & C. Beck & Piponnier et al., 1993 \\
\hline 35 & Lyon (Rhône) & Boulevard périph. nord & $1300-1500$ & V. Forest & Speller, Forest, 1996 \\
\hline & & Place de la Bourse & $1400-1700$ & V. Forest & Arlaud et al., 1990 \\
\hline & & Place de la République & $1500-1600$ & V. Forest & Arlaud et al., 1992 \\
\hline & & Place des Célestins & $600-900$ & V. Forest & Arlaud et al., 1993 \\
\hline & & Place des Terreaux & $1550-1600$ & V. Forest & Arlaud, Forest, 1995 \\
\hline 36 & Meyzieu (Rhône) & La Chapelle & $900-1100$ & V. Forest & Coquidé, Forest, 1994 \\
\hline 37 & Poncin (Ain) & Le Chatelard & $675-725$ & V. Forest & Étude en cours (dir. E. Boucharlat) \\
\hline 38 & Rochefort-en-Valdaine (Drôme) & Le Château & $1300-1400$ & V. Forest & Forest, 1987 \\
\hline 39 & Saint-Paul-Trois-Châteaux (Drôme) & Place du Marché & $1000-1400$ & V. Forest & Forest, 1998a \\
\hline
\end{tabular}


- 20 avant J.-C./20 après J.-C. ;

- 20-80 après J.-C. ;

- $60-150$;

- 120-260;

- 260-400) ;

- 400)-500.

La répartition des contextes du haut Moyen Âge est établie d'après le terminus post quem, siècle par siècle, quel que soit le terminus ante quem qui cependant est toujours antérieur à l'an Mil. Les ensembles chronologiques sont les suivants :

- $800-1300$;

- $1300-1500$;

- 1400-1500.

À la charnière des deux premières périodes se trouvent les mesures prises sur des os issus de niveaux archéologiques datés du $\mathrm{XI}^{*}$ au $\mathrm{XV}^{e}$ s., tandis que le dernier intervalle débute fin $\mathrm{XV}^{\mathrm{c}}$-début $\mathrm{XVI}^{\mathrm{e}} \mathrm{s}$. marquant l'entrée dans la période moderne. La réalité archéologique fournit des contextes datés parfois de manière large qui recouvrent deux intervalles chronologiques. Le chevauchement des périodes nécessite donc que la lecture de l'évolution diachronique se fasse de manière fluide. $\mathrm{Si}$ l'intervalle est trop long, et ce surtout lors des périodes " charnières ", les données du site ont été rejetées. Par ailleurs, les mesures issues de plusieurs sites, d'une même région ou de régions différentes, ont pu être regroupées si elles appartenaient au même intervalle chronologique.

Les sites archéologiques d'où proviennent les mesures de métatarses sont énumérés selon les régions administratives actuelles et classés à l'intérieur de cellesci par ordre alphabétique. Par souci de lisibilité, deux cartes sont proposées: l'une regroupant les sites datés des périodes gauloise et gallo-romaine (fig. 3 et tabl. I), et l'autre les sites des époques médiévale et moderne (fig. 4 et tabl. II). Globalement, nous avons recueilli 446 mesures de grande longueur (GL), 832 mesures de largeur proximale (Bp) et 1054 mesures de largeur distale (Bd), provenant de 109 sites différents. Ces chiffres peuvent paraitrc ćlevés mais ils restent très faibles compte tenu de l'aire géographique couverte et de la durée de la chronologie. Si certaines régions ont livré de nombreuses données métriques, d'autres sont "vides " de toute information. En outre, le nombre de données métriques disponibles pour les années 600 à 1700 (soit dix siècles) est faible, car peu de mesures brutes ont été publiées pour les sites médiévaux et modernes de la France du Nord, réduisant ainsi les possibilités de comparaison à l'échelle de la France : GL, 67 mesures sur un total de 446 (15\%) ; Bp, 169 sur 832 (20\%) ; Bd, 224 sur 1054 (21\%).

\section{COMMENTAIRE DES TABLEAUX}

\section{GRANDE LONGUEUR (GL)}

Les bovins du I ${ }^{\mathrm{cr}} \mathrm{s}$. avant notre ère se caractérisent par des métatarses "petits " et " moyens " accompagnés de quelques métatarses " grands" (fig. 6 et tabl. III). L'importante série de mesures provenant du site de Villeneuve-Saint-Germain illustre bien cette constatation (Auxiette, 1994). Une telle répartition des données métriques se maintient environ jusqu'au milieu du $\mathrm{I}^{\mathrm{er}} \mathbf{s}$. de notre ère, date à partir de laquelle une étape décisive est franchie: les longueurs ne correspondent plus aux valeurs " petites " et " moyennes " mais se concentrent dans les " grandes " et " très grandes ", en particulier pour les régions provençales et languedociennes. Dans les autres régions, les valeurs glissent simplement des "moyennes" aux " grandes ». On remarque une raréfaction des os "petits". À partir du milieu du II" s. et jusqu'à la fin du VII" s., la situation est assez stable avec, cependant, une raréfaction des os «très grands " et une augmentation de la proportion de "grands" dès le $V^{e} s$. Puis, les métatarses des $\mathrm{IX}^{\mathrm{c}}, \mathrm{X}^{\mathrm{c}}$ et $\mathrm{XI}^{\mathrm{c}} \mathrm{s}$. subissent une forte diminution de la corpulence et les grandes longueurs se concentrent à nouveau vers les valeurs "petites" et " moyennes ". Les quelques données des $\mathrm{XIV}^{*}$ et $\mathrm{XV}^{*} \mathrm{~s}$. correspondent en partie aux valeurs " grandes " et " très grandes".

\section{INDICE DE GRACILITÉ (SD X 100/GL)}

Les graphiques obtenus lors du croisement de l'indice de gracilité diaphysaire (SI) $\times 100 / \mathrm{GL}$ ) ${ }^{11}$ et de la

11. Par sonci de comparaison anec divers trataux, les graphiques présentent les variations de la grande longueur en fonction de lindice de gracilité, lui-même calculé à partir de la grande longueur. Il serait plus exact de suive la variation conjointe de deux variables mathématiquement indépendantes: la largeur diaphysaire (SD) et la grande longueur (Gl.). I.es résultats de l’étude de la largeur minimale de la diaphyse ont écé consignés dans Forest, Rodet-Belarbi, 1998, p. 1046. 

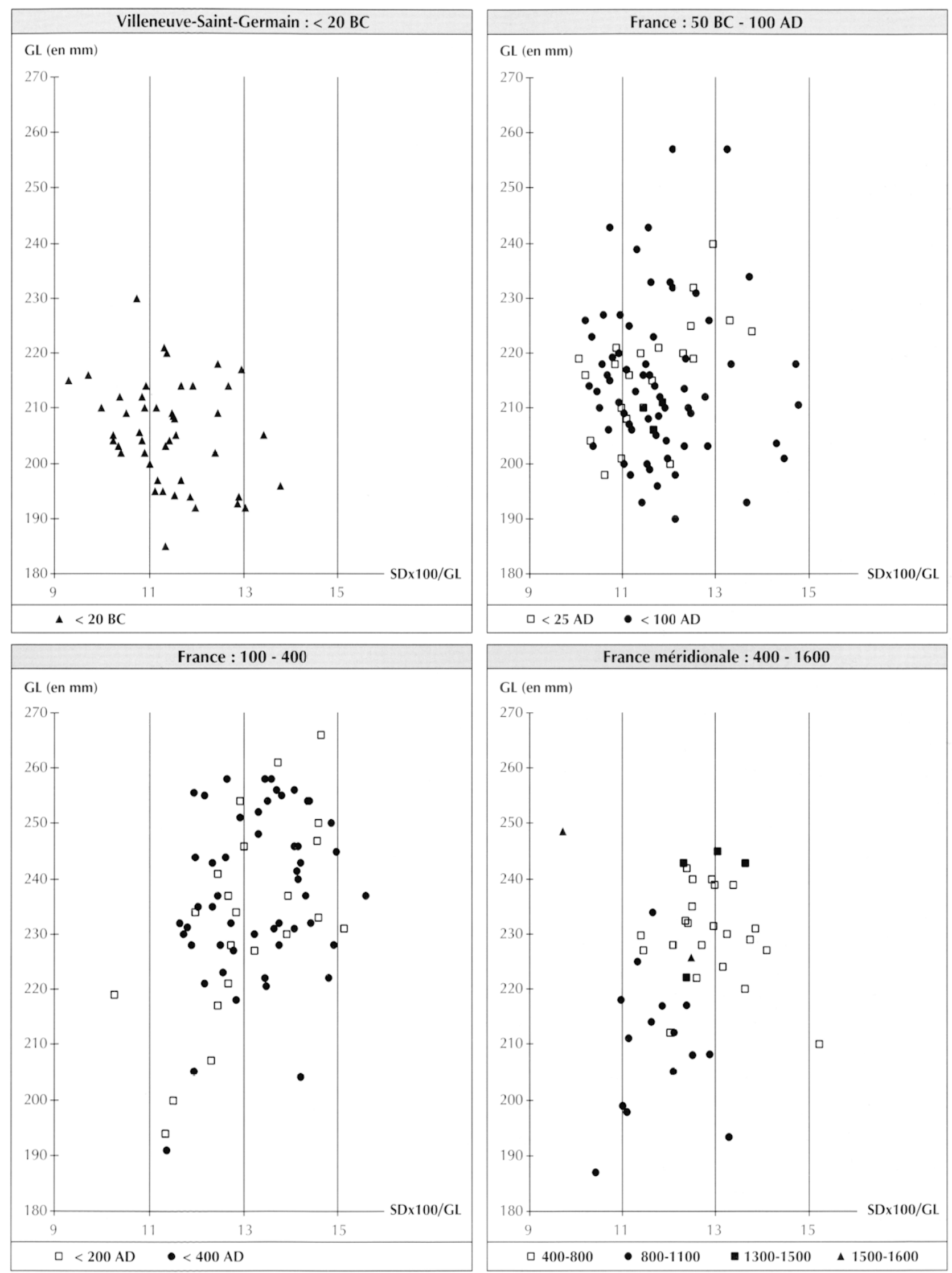

Fig. 5 - Évolution chronologique de l'indice de gracilité diaphy:saire (SI) $\times 100 / G L)$ en fonction de la grande longueur du métatarse. (il, grande longueur; SD), diamètre le plus fin de la diaphyse (DAO V. Forest, I. Rodet-Belarbi, INRAP). 
Tabl. III - Récapitulatif des grandes longueurs (GL) des métatarses de bovins : T(; taille au garrot; $M$, mâle; $I$; femelle; $T P Q$, terminus post quem ; TAQ terminus ante quem.

longueur totale $(\mathrm{GL})$ indiquent que la majorité des métatarses, entre 50 avant J.-C. et 100 après J.-C., compose un morphotype proche de celui antérieur à 20 avant J.-C. : la gracilité est la même, centrée autour de 11,5 , mais un allongement de la diaphyse se dessine (fig. 5). Autour de ce dense nuage de points gravitent des os de grande taille non connue précédemment. Ils sont, soit plus grands mais de même gracilité, soit aussi longs mais plus larges. Ils sont proportionnellement aussi nombreux avant 50 après J.-C. qu'après. À partir de 100 après J.C., les métatarses sont plus grands et plus larges. Les " moyens " et les "petits " se raréfient et semblent résiduels. De 400 à 800 , le nuage de points se regroupe autour d'un indice de gracilité de l'ordre de 13 , avec de grandes longueurs. La période suivante, 800-1200, est caractérisée par une réduction des os, moins longs et plus graciles. Toutefois, en l'état de notre échantillon, la valeur de l'indice de gracilité est centrée autour de 12 et ne descend pas en dessous de 11 comme à Villeneuve-Saint-Germain. Les quelques données des XIV'-XVI"s. sont similaires à celles de l'Antiquité tardive.

\section{LARGEUR DE L'EXTRÉMITÉ PROXIMALE (Bp)}

La fin de la période gauloise est illustrée par une répartition des valeurs entre les classes " petite " et "moyenne » (tabl. IV). À partir du règne d'Auguste (12 avant J.-C./14 après J.-C.), cette situation se maintient. Les premières valeurs « très grandes » apparaissent au cours du $\mathrm{I}^{\mathrm{er}} \mathrm{s}$. de notre ère accompagnées d'une présence importante de "petites " durant la première moitié de ce siècle. Ces dernières se raréfient au profit des valeurs « moyennes » et " grandes " dès la période flavienne (69-96 après J.-C.). Les métatarses aux largeurs " très grandes " sont présents du II ${ }^{e} s$. à la fin de l'Antiquité tardive. Dès que le $\mathrm{VII}^{\mathrm{e}} \mathrm{s}$. est franchi, les " très grandes " valeurs disparaissent. Puis, c'est au tour des valeurs " grandes " dès le VIII" s., et de manière très nette au IX $\mathrm{IX}$. En revanche, les valeurs "petites" se multiplient. Cet échantillon composé de « petites " et " moyennes » largeurs se maintient jusqu'au XII ${ }^{e}$ s. Les " petites" valeurs se raréfient à nouveau tandis que les " grandes " réapparaissent à partir des périodes chronologiques dont le terminus ante quem correspond au $\mathrm{XIII}^{\mathrm{e}}$ s., et surtout au XIV ${ }^{\mathrm{e}}$ s. Enfin, les valeurs se stabilisent dans les classes " moyenne " et " grande " dès le XIVe s., et jusqu'au XVIII ${ }^{\mathrm{e}} \mathrm{s}$. La classe des " très grandes " mesures possède un faible effectif.

\section{LARGEUR DE L'EXTRÉMITÉ DISTALE (Bd)}

L'évolution de cette mesure est moins nette que la précédente, la distribution des valeurs étant beaucoup plus large (tabl. V). Mais une évolution chronologique similaire à celle de la largeur de l'extrémité proximale est perceptible : concentration des données métriques dans les intervalles " petit " et " moyen " avec quelques mesures " grandes " avant le changement d'ère, apparition des valeurs " très grandes " dès le milieu du ${ }^{\text {er }}$ s. de notre ère, raréfaction des mesures " petites" au II" $s$. Dès ce siècle, et jusqu'au cours du VII' $s$., la situation est stable. La grande majorité des valeurs sont "moyennes" et " grandes " avec occasionnellement quelques " petites " et " très grandes ". Le repli général des valeurs s'effectue vers le VII' s., mis à part à Beauvais où les valeurs " très grandes" persistent au cours des $\mathrm{IX}^{\mathrm{e}}-\mathrm{X}^{\mathrm{e}} \mathrm{s}$. Il faut attendre le milieu du XIII' ${ }^{\circ}$ s., et plus sûrement le début du XIVcs., pour les voir augmenter. À Lyon et à Toulouse, l'entrée dans le XVI" s. s'accompagne d'une raréfaction des valeurs " moyennes ».

En résumé, l'échantillon de données métriques du métatarse disponible à ce jour, même s'il est encore très insuffisant, permet d'isoler sept séquences: une première se termine à la fin de l'âge du Fer, la deuxième va de la fin du $\mathrm{I}^{\mathrm{er}}$ s. avant J.-C. à la fin du $\mathrm{I}^{\mathrm{er}}$ s. après J.-C., une troisième commence au $\mathrm{II}^{\text {e }} \mathrm{s} .{ }^{12}$ pour se terminer aux premiers siècles du haut Moyen Âge, une quatrième correspond aux $\mathrm{VII}^{\mathrm{e}}$ et $\mathrm{VIII}^{\mathrm{e}} \mathrm{s}$., une cinquième va du $\mathrm{IX}^{\mathrm{e}}$ au $\mathrm{XII}^{\mathrm{e}}$ s., une sixième comprend les XIII ${ }^{e}$ et XIV ${ }^{\mathrm{e}}$ s., et la dernière commence au $\mathrm{XV}^{\mathrm{c}} \mathrm{s}$. et se poursuit jusqu'au

12. Très récemment mis au jour à Perpignan (Pyrénées-Orientales), un lot d'os de "grandes" dimensions, dont des métatarses "grands " et " très grands "d'indice de gracilité proche de 13,7, suggère que les grands bovins seraient présents en Narbonnaise dès les années 50-70 après J-C. (étude inédite). 


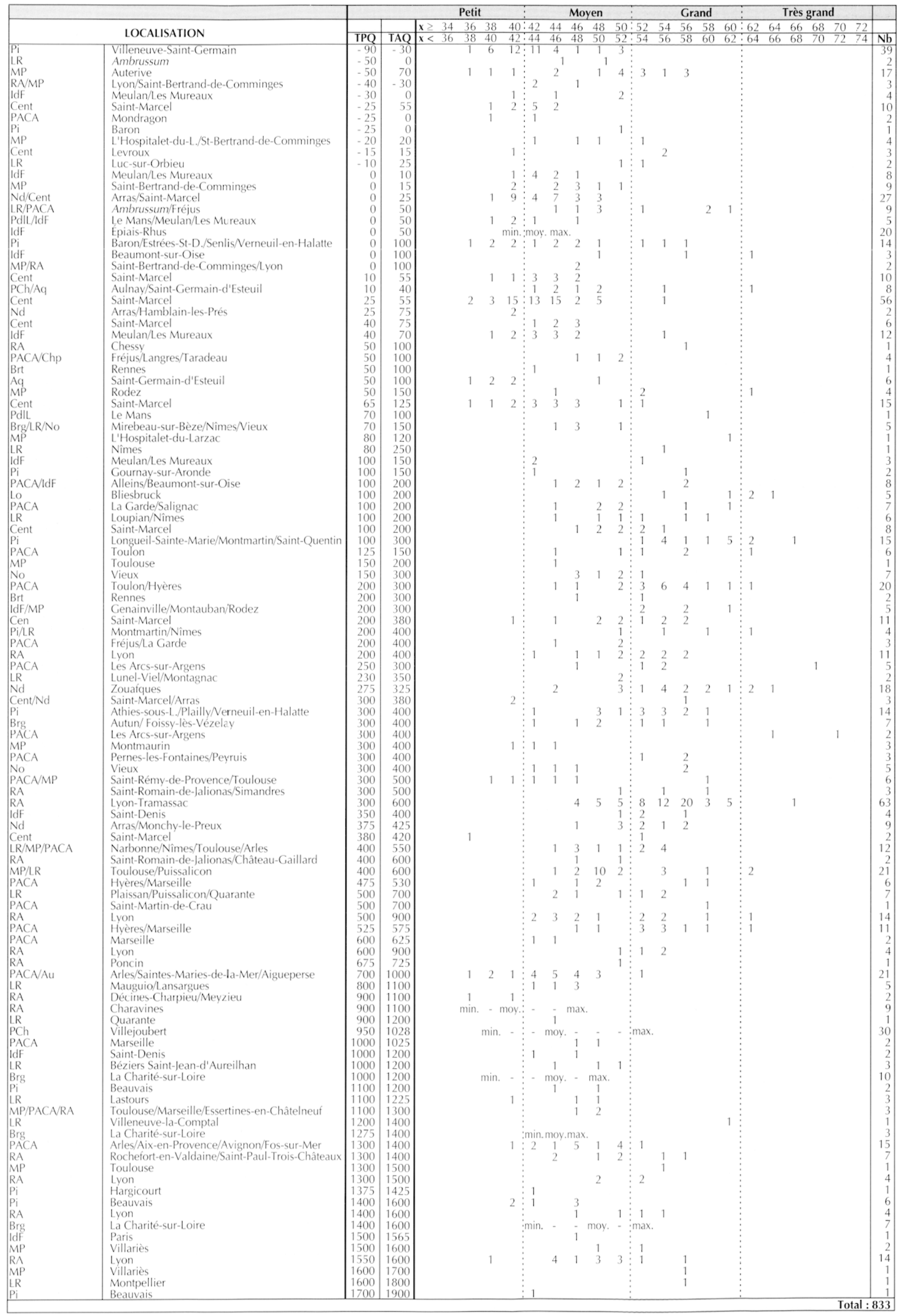


Tabl. IV - Récapitulatif des largeurs proximales $(B p)$ des métatarses de bovins : $T P Q$ terminus post quem; TAQ, terminus ante quem.

XVIII ${ }^{e}$ s. Chacune se caractérise par une évolution des mesures de la longueur et des largeurs. Ainsi, entre la première et la deuxième séquence, l'allongement et l'élargissement des os se font harmonieusement avec conservation de la gracilité. Puis, le passage entre la deuxième et la troisième période est, principalement, marqué par un élargissement des métatarses. Ensuite, on observe une simple décroissance des dimensions sans transformation dans leur rapport. Cet élargissement se poursuit entre la quatrième et la cinquième séquence et aboutit à une robustesse supérieure à celle des os de La Tène finale, à longueur égale. En revanche, l'augmentation des dimensions au cours de la sixième période conduit, dans la septième, à des ossements proches de la période II $^{\mathrm{e}}$ s.-début du haut Moyen Âge. Toutefois, le rapprochement est plus ou moins net selon la mesure. Alors que les valeurs maximales de la largeur de l'extrémité distale sont similaires, celles de la grande longueur et de la largeur de l'extrémité proximale au bas Moyen Âge et aux Temps modernes sont en net retrait par rapport à celles de l'Antiquité.

\section{DONNÉES ARCHÉOLOGIQUES ET GÉOGRAPHIQUES}

Il est difficile, à ce jour, de prendre en compte les contextes archéologiques dans leurs moindres détails, compte tenu de la petitesse des séries sur la plupart des sites. Seuls trois d'entre eux ont été observés plus finement en raison d'une répartition particulière des valeurs. Ils totalisent, en effet, 27 des 42 longueurs " très grandes » recensées entre 200 et 575 . Il s'agit d'une zone de rejets d'une éventuelle "boucherie " (rue Tramassac à Lyon, cf. Arlaud et al., 1994), du comblement d'une zone portuaire (Les Riaux à Toulon, cf. Leguilloux, 1994) et " de la cave d'une villa" dont les niveaux de remblaiements contenaient "une grande quantité d'ossements de bœuf bien conservés, retrouvés complets " (Wolphus à Zouafques, Pas-de-Calais, cf. Lepetz, 1995a, p. 52). L'important volume de ces trois lots osseux étend l'échantillon des " grandes " longueurs vers les " très grandes " valeurs durant la période 200-575. Ils amplifient ainsi la variation de la grande longueur, et donc de la hauteur au garrot. Mais ce changement ne se retrouve pas lors de l'examen des largeurs proximale et distale, car ces ensembles ne se singularisent plus parmi le grand nombre de mesures ${ }^{13}$. La nature particulière des activités artisanales entraînant ces dépôts archéologiques a peut-être provoqué un regroupement important d'ossements provenant d'animaux choisis pour leur morphologie : animaux corpulents pour une boucherie, animaux hauts sur pattes (donc de longs métapodes) pour le travail de l'os... Une telle sélection déforme notre vision générale du cheptel et ne peut être "gommée " que grâce à un effectif élevé de mesures.

Une étude a été tentée par région, dans l'intention de découvrir où et quand les bovins de grande corpulence “ apparaissaient " en premier. Mais ce travail est resté décevant en raison de la faiblesse des séries régionales qui, de plus, n'offrent jamais de continuité chronologique totale (Forest, Rodet-Belarbi, 1998, p. 1034). Quelques résultats ponctuels ont attiré notre attention mais sont à affiner par une nouvelle collecte de données. Par exemple, les données métriques sont similaires, dans de nombreux cas, au sein d'une même région, ou d'une région à l'autre, pour une même fourchette chronologique, ce qui a permis les regroupements de données isolées provenant de divers sites. Mais, les métatarses du Moyen Âge central en France septentrionale ne se différencient guère de ceux de la France méridionale, au contraire de ceux des siècles suivants qui s'inscrivent dans les valeurs « basses » du sud de la France ${ }^{14}$.

\section{INTERPRÉTATION BIOLOGIQUE}

La détermination du degré d'homogénéité de la population bovine à l'origine de l'échantillon archéo-

13. On comprendra ici à quel point l'ajout ou le retrait du corpus des données métriques d'un ou plusieurs sites peut influer sur les résultats, en particulier les moyennes sur lesquelles reposent quelques travaux majeurs.

14. Pour le bas Moyen Âge, des variations interrégionales commencent à surgir, par exemple entre la moitié occidentale des Pyrénées et la région toulousaine (Carrère et al., à paraître). Mais, les échantillons disponibles sont encore trop peu nombreux pour permettre d'éliminer les facteurs de tri des animaux autres que la seule géographie au sein des assemblages osseux. 


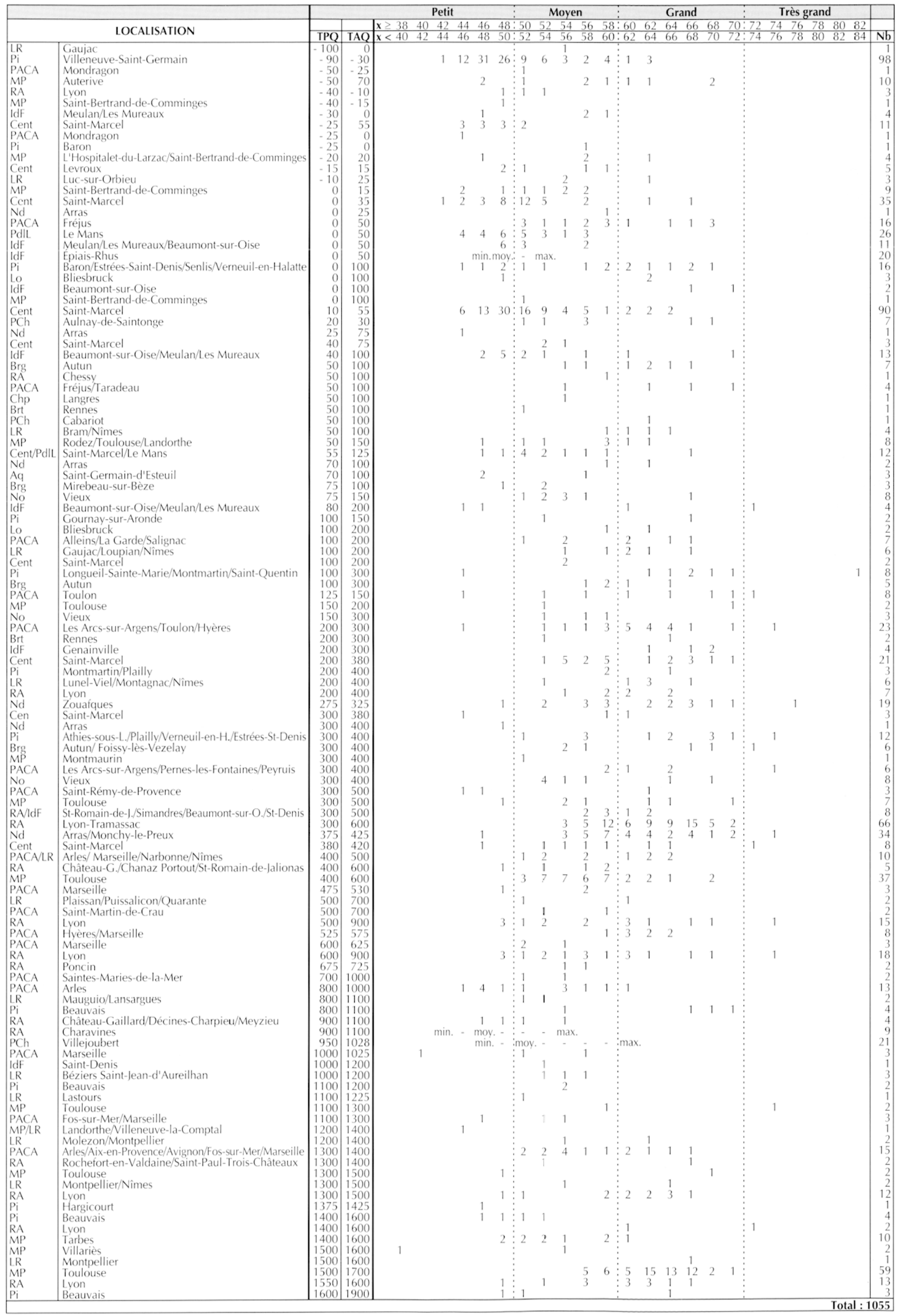


Tabl. V - Récapitulatif des largeurs distales (Bd) des métatarses de bovins : TPQ terminus post quem ; TA $Q$, terminus ante quem.

logique est primordiale, car elle permet d'apprécier la représentativité du lot étudié par rapport à la ou les populations initialement présentes sur le site et de déterminer la présence d'un ou plusieurs morphotypes (Guintard, 1998, p. 754). L'étude menée par C. Guintard sur les métapodes des bovins actuels de race charolaise, des bovins marrons de l'île d'Amsterdam et de ceux des populations bovines fossiles a montré qu'il est possible d'employer un critère d'analyse simple: la variabilité maximale $^{15}$ (Guintard, 1996, p. 155 sqq.). Dans une population racialement homogène, elle ne dépasse pas $30 \%$ pour la grande longueur et $60 \%$ pour les largeurs. Appliquée à notre lot de métatarses, on constate que dans aucune phase chronologique, et plus particulièrement lors des périodes de transformation des morphologies, les variabilités maximales ne dépassent ces valeurs extrêmes (Forest, Rodet-Belarbi, 1998, p. $1052 ; 2000$ ). En conséquence, l'ostéométrie ne permet pas de révéler la coexistence de morphotypes différents. Il est possible, en revanche, de mettre en évidence quatre groupes homogènes de métatarses qui se succèdent chronologiquement, mais qui ne cohabitent pas dans les périodes de transition qui s'intercalent entre elles: La Tène finale, II ${ }^{\mathrm{e}}$ s.-début du haut Moyen Âge, IX'-XII" s., XIV"-XVIII's. (fig. 6 et 7). Entre les différents ensembles, le passage se fait progressivement, sans rupture franche. Les augmentations ont lieu sur une durée de 150 ans entre la conquête romaine et le tournant des $\mathrm{I}^{\mathrm{er}}-\mathrm{II} \mathrm{I}^{\mathrm{e}} \mathrm{s}$., avec deux phases d'accélération à ces périodes-là, et d'une centaine d'années entre le XIII ${ }^{c}$ s. et le XIV ${ }^{e}$ s. La diminution des dimensions au haut Moyen Âge est beaucoup plus lente puisqu'elle semble s'étaler sur trois ou quatre siècles entre le $\mathrm{V}^{\mathrm{c}} \mathrm{s}$. et le VIII' $s$.

La diversité et le nombre des sites pourvoyeurs d'os autorisent à admettre que dans chaque échantillon chronologique mâles et femelles sont présents. On imagine mal que dans une période donnée, et aucun écrit n'abonde dans ce sens, la consommation de viande d'un des sexes soit prohibée, en particulier ici celle de

15. La rariabilité maximale est définie ainsi : $V(\%)=$ (maximini)/mini. Pour plus de détails, nous renvoyons le lecteur aux travaux de C. Guintard (1996, 1997, 1998). vache. En conséquence, l'évolution des valeurs les plus basses des échantillons, qui globalement sont celles appartenant à des animaux femelles étant donné le dimorphisme sexuel plus ou moins marqué chez les bovins, est partiellement révélatrice de l'évolution globale d'une population. Cette constatation permet de contourner la querelle des sexes. Les raréfactions, voire les disparitions des "petites" valeurs, au cours du $\mathrm{I}^{\mathrm{rr}} \mathrm{s}$. après J.-C. et du bas Moyen Âge, ou, au contraire, leur multiplication durant le Moyen Âge central, couplées aux mouvements des " grandes " et " très grandes " constituent un argument supplémentaire en faveur d'une transformation de la population initiale plutôt que d'une importation de morphotypes différents.

Attardons-nous sur le métatarse du squelette du plus grand des deux bovins découverts à Gournay-sur-Aronde dans le comblement d'un puits " dont le rebouchage peut être daté de la première moitié du deuxième siècle par les céramiques" (Brunaux, Méniel, 1983, p. 17). Il est le seul publié dont nous puissions nous servir comme référence pour les grands bovins dits italiques et importés avant la conquête ou dans les années qui ont suivi. Ses mesures sont indiquées dans les tableaux III, IV et $\mathrm{V}$ et sur la figure 8 . Il est aisé de constater que la grande longueur correspond à une " très grande " valeur et les largeurs proximale et distale à des " grandes " valeurs. Toutes les trois sont situées parmi les mesures les plus communes durant les $\mathrm{II}^{\mathrm{c}}-\mathrm{V}^{\mathrm{c}} \mathrm{s}$., auxquels il appartient. En opposition, aucun des quelques grands métatarses datés d'avant la conquête ou dans les années qui ont suivi et dont les mesures ont été publiées ne présente à la fois la double importance de la longueur et des largeurs : ils peuvent être aussi longs mais sont alors de gracilité " gauloise "; ils peuvent être aussi larges mais sont alors courts.

\section{INTERPRÉTATION ZOOTECHNIQUE}

C. Guintard a montré que, chez les bovins charolais actuels, la corrélation entre la longueur du métatarse et la hauteur de l'animal est étroite, mais elle devient moindre entre la longueur de cet os et le poids de carcasse de l'animal dont il provient (Guintard, 1996, 


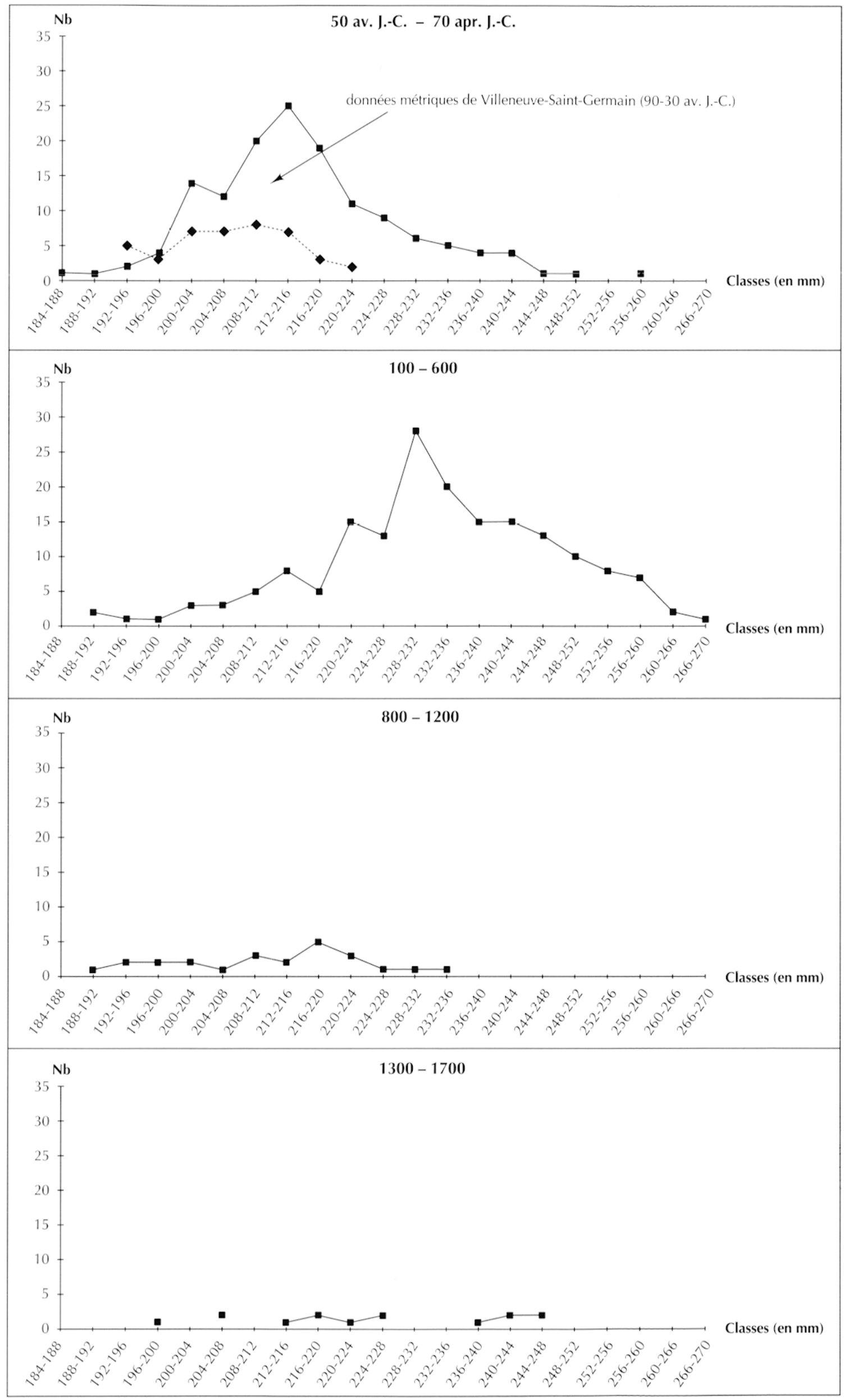

Fig. 6 - Courbes récapitulatives de la grande longueur (GL) des mélatarses : nombre d'os par classe (DAO V. Forest, I. Rodet-Belarbi, INRAP). 


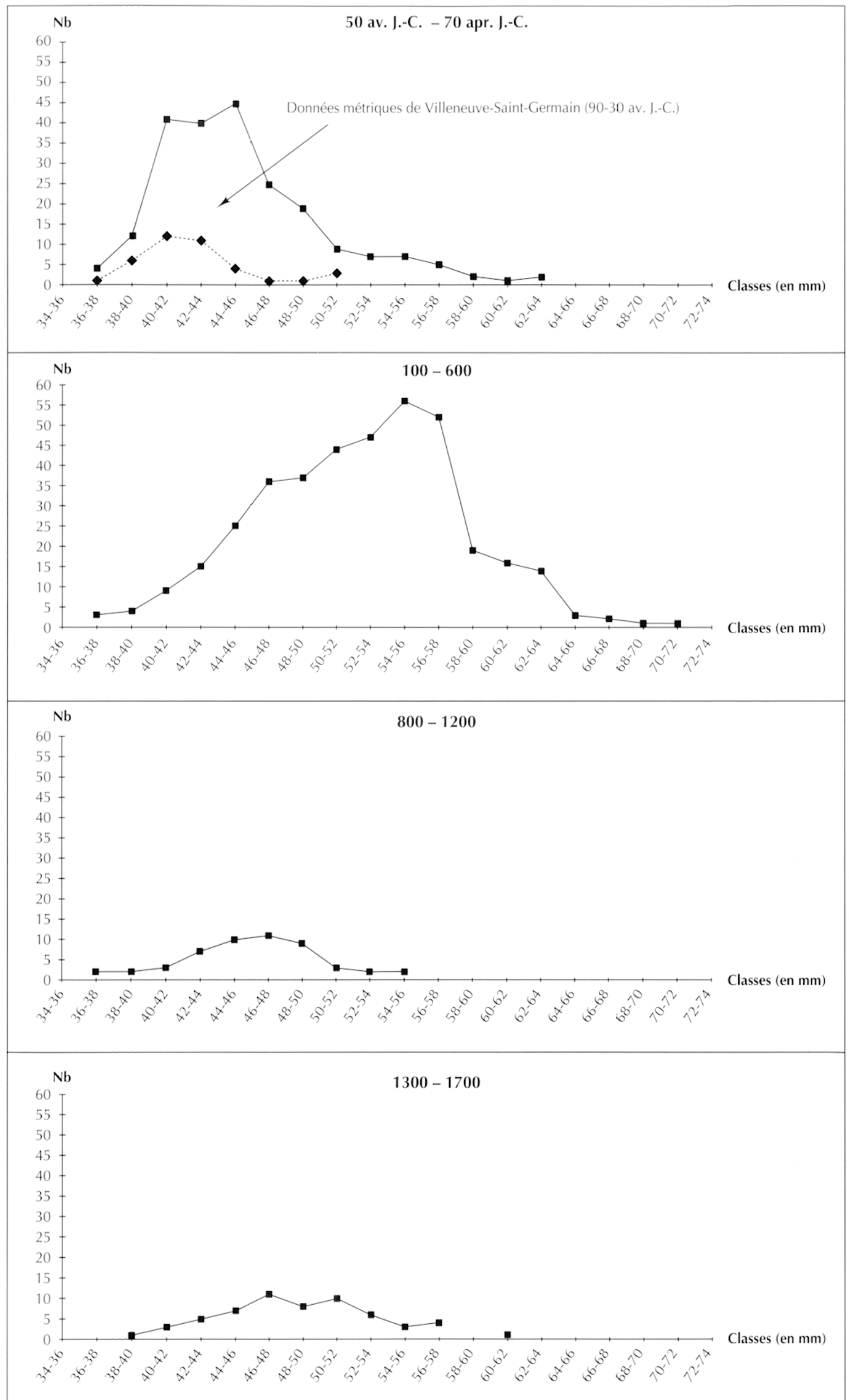

Fig. 7 - Courbes récapitulatives de la largeur proximale $(B p)$ des métatarses : nombre d'os par classe (DAO V. Forest, I. Rodet-Belarbi, INRAP). 

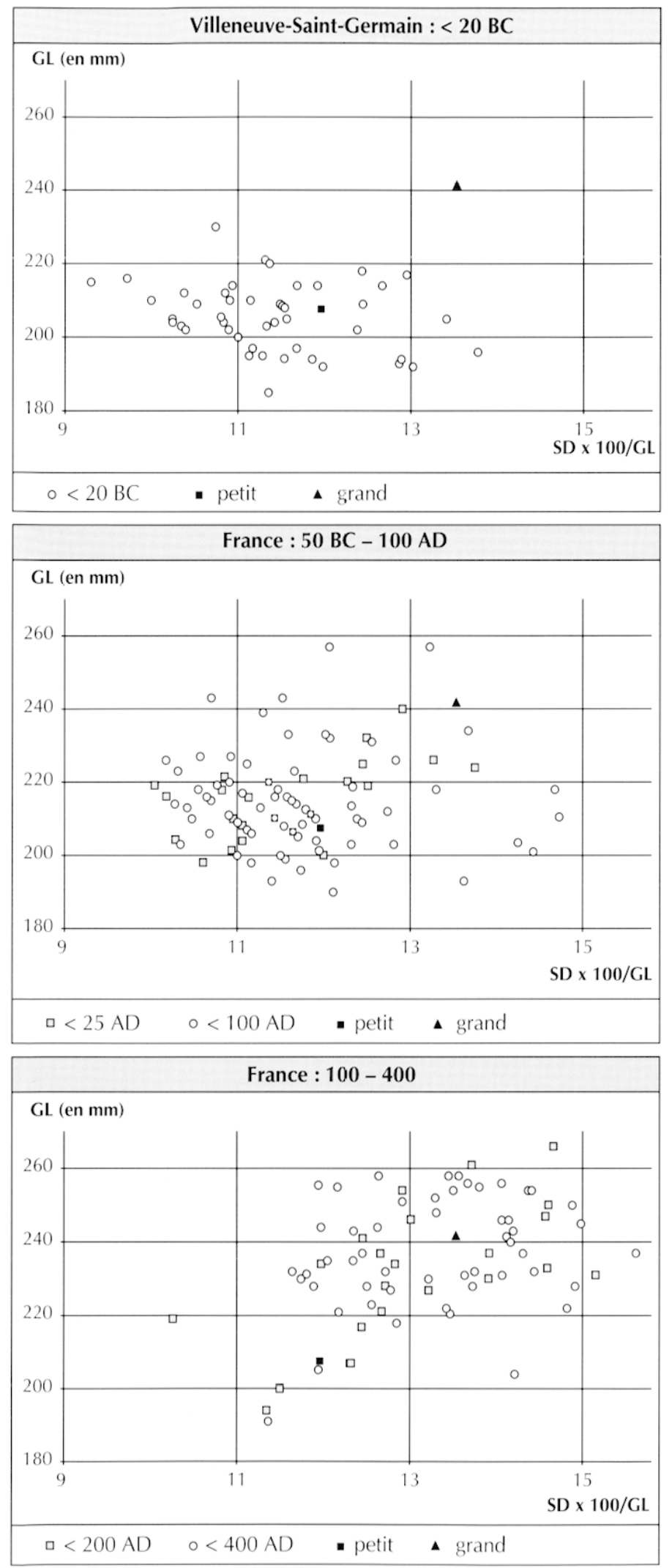

Fig. 8 - Indices de gracilité diaphysaire (SI) x 100/(GL) en fonction de la grande longueur $(G I)$ des deux métatarses de Gournay-sur-Aronde issus d'un puits comblé durant la première moitié du II s. (DAO V. Forest, I. Rodet-Belarbi, INRAP, d'après Forest, Rodet-Belarbi, 1998). p. 137 et 140). Rappelons que les largeurs de la diaphyse et des extrémités proximale et distale sont principalement corrélées au poids de la carcasse, mais également à la hauteur au garrot. Ces relations nous permettent d'envisager l'évolution de la corpulence des populations bovines à partir de notre échantillon de métatarses.

Dès la conquête, ou peut-être même avant, certains bovins deviennent plus hauts et d'autres plus forts. Ils ne possèdent pas un morphotype différent du noyau primitif gaulois dont ils peuvent être issus et duquel ils ne forment pas un ensemble distinct. Cette évolution précoce aboutit à une population stable durant le $\mathrm{I}^{\mathrm{er}} \mathrm{s}$. après J.-C. De la fin du Irr s. au $\mathrm{II}^{\mathrm{e}} \mathrm{s}$., les bovins dans leur ensemble grandissent et s'alourdissent. La totale disparition des individus " petits " et l'importante régression du nombre d'individus " moyens » laisseraient supposer que le " nouveau " bovin résulte de l'évolution de la population précédente. Ce dernier se maintient du $\mathrm{II}^{\mathrm{e}} \mathrm{s}$. au $\mathrm{VI}^{\mathrm{C}} \mathrm{s}$. Seuls les animaux inscrits dans cet intervalle chronologique précis peuvent être appelés " grands bœufs ", en tant que population zootechniquement individualisée. C'est à cette population qu'appartient le "grand bœuf " de Gournay-sur-Aronde, puisque les données métriques fournies par son métatarse permettent de dire qu'il provient d'un individu haut, ce qui avait été mis en évidence par le calcul de la hauteur au garrot (Brunaux, Méniel, 1983, p. 17), et surtout robuste, ce que nous soulignons par notre enquête. Son morphotype ne se retrouve pas dans les périodes antérieures et ne peut donc pas être celui qui, selon ces auteurs, aurait été importé.

La corpulence des bovins se réduit progressivement au cours du haut Moyen Âge. Cette décroissance, mal perceptible à partir du métatarse seul, faute de données métriques disponibles, est mise en évidence par les mesures des autres segments osseux (Forest, RodetBelarbi, 2000). Les bovins de la période IX'-XII ${ }^{c}$ s. sont aussi petits que ceux de La Tène finale mais plus robustes. C. Guintard (1997) arrive à une conclusion similaire d'après les métapodes des bovins découverts dans les niveaux archéologiques datés de l'an Mil du site d'Andone à Villejoubert (Charente). Les bovins du $\mathrm{XIII}^{\mathrm{s}} \mathrm{s}$. et des siècles suivants retrouvent une corpulence comparable à celle de la grande majorité des bovins romains mais sans les individus très hauts et avec des différences morphologiques plus ténues dans les articulations (cf. largeurs Bp et Bd). 
Comment expliquer l'évolution de ces populations bovines? L'hypothèse d'une importation par les Romains d'un "grand bouf " ne s'impose pas en première lecture des tableaux. En effet, si tel était le cas, dans une fourchette chronologique étroite, deux populations parfaitement différenciées par une répartition bimodale des valeurs ostéométriques devraient coexister ${ }^{16}$. Compte tenu de la répartition des données métriques, une importation massive ne pourrait être envisagée qu'au cours du II' $s$. après J.-C. Il y aurait alors eu une élimination systématique des animaux " moyens " et une importation de " grands " et " très grands" individus. Mais une arrivée massive et simultanée d'animaux, à l'échelle de toute la France gallo-romaine, suppose un immense réservoir de troupeaux et une volonté planificatrice forte dont d'autres témoignages auraient dû nous parvenir. Il n'est actuellement pas possible d'affirmer que ces " grands bœufs » dits " romains " viennent d'Italie. En effet, les données métriques brutes disponibles pour la péninsule Italique sont peu nombreuses. En outre, elles ne sont pas rattachées à des périodes chronologiques fines mais à un ensemble nommé "période romaine " qui mélange l'avant et l'après de la seconde moitié du $\mathrm{I}^{\text {er }} \mathrm{s}$. après J.-C. L'exemple est donné par A. Riedel qui, dans deux synthèses portant l'une sur la côte adriatique et la région des lacs (1986) et l'autre sur le nord-est de l'Italie (1996), dessine le changement de la corpulence des bovins, mais dans une chronologie trop large pour en saisir le détail ${ }^{17}$.

16. Il existe une exception, le site de La Bourse à Marseille où, comme L. Jourdan l'avait pressenti (1976) et comme C. Guintard l'a confirmé (1998), deux morphotypes se côtoient. De plus, la forte densité d'os aux dimensions "petites" est unique dans notre échantillon entre le III" et le $\mathrm{V}^{*} \mathrm{~s}$. après J.C. Faut-il considérer ce site comme une singularité locale, ou faut-il supposer un mélange d'ossements appartenant à des périodes chronologiques différentes?

17. L'ironie de l'échantillonnage nous donne une mesure pour l'extrémité distale d'un métatarse découvert dans les niveaux datés des périodes flavienne et antonnienne (II A-C) à la villa Sette Fïnestre: Bd $=41 \mathrm{~mm}$ [: 41] (Carandini dir., 1985). Elle se situe en deçà des valeurs du site de Villeneuve-Saint-Germain (cf. tabl. V, p. 290). Récemment, l'étude d'un lot de vestiges fauniques de la période 30 avant J.-C./15 après J.-C. dans la villa périurbaine du Clos de la Lombarde à Narbonne n'a livré que des restes de bovins aux dimensions " petites ", " moyennes" et quelques " grandes" (Forest, à paraître). Narbonne est une colonie romaine depuis 118 avant J.-C., capitale de région dont les campagnes environnantes sont réputées avoir accueilli des colons italiens. Aussi, il serait surprenant que les grands bovins n'aient pas été importés d'Italie durant le siècle écoulé depuis la conquête de la Narbonnaise, alors qu'ils l'avaient été au même moment en Gaule
Par analogie à la période antique, il faudrait aussi évoquer une importation du même ordre au bas Moyen Âge qui, à notre connaissance, n'a pas été signalée par les documents écrits relativement abondants à cette époque. À l'inverse, pour expliquer la présence des "petits " bovins au Moyen Âge, on pourrait imaginer que les divers peuples immigrants aient voulu, eux aussi, imposer leurs bovins - dont on sait qu'ils sont petits en Germanie non latinisée - (Driesch, 1992; Peters, 1998). Cette hypothèse ne résiste pas à l'observation des données ostéométriques car il n'y a pas, ici non plus, juxtaposition de deux populations individualisées. De plus, la diminution de la corpulence surviendrait tardivement vers les VII $^{\mathrm{c}}$-VIII ${ }^{\mathrm{c}}$ s., c'est-à-dire plutôt postérieurement à l'installation des peuples germaniques en Gaule. Par ailleurs, il ne peut s'agir d'un " retour " du " petit bœuf " de La Tène puisque le " petit » bovin du Moyen Âge possède ses qualités propres. Ce dernier est probablement le fruit d'une lente adaptation du bovin de l'Antiquité tardive au monde médiéval, car, pour des raisons qui nous échappent encore, les sociétés qui les élèvent n'ont pas eu besoin de grands animaux.

Aussi, pour expliquer les deux augmentations de corpulence des bovins qui, somme toute, ne dépassent guère les $15 \%^{18}$, nous préférons proposer des mécanismes plus simples qui ne font que transformer les populations initiales. Nous évoquerons, en premier lieu, le régime alimentaire, en particulier chez les jeunes. Nous suivons ainsi L.-F. Grognier et H. Magne, professeurs à l'École vétérinaire de Lyon : "Chez les bœufs beaucoup plus que chez les chevaux et les autres herbivores, la taille dépend de la nourriture [...] les races bovines chétivement nourries se rabougrissent rapidement de génération en génération " (Grognier, Magne, 1841, p. 85), et

chevelue. De plus, il serait étonnant que durant la seconde moitié du $I^{\cdot T} \mathbf{s}$. il n'y ait pas eu de grands bovins en Narbonnaise alors qu'il y en avait en Gaule nouvellement conquise.

18. Cette valeur, $14,4 \%$, est obtenue en prenant $208 \mathrm{~mm}$ comme valeur modale approximative de la grande longueur du métatarse du bouf gaulois et $238 \mathrm{~mm}$ pour celle de son équivalent romain (cf. tabl. III, p. 286). Des valeurs proches peuvent être calculées, $16,4 \%$ à partir des métatarses des deux bovins du puits de Gournay-sur-Aronde, approximativement $207 \mathrm{~mm}$ pour le petit, $241 \mathrm{~mm}$ pour le grand (lecture sur cliché photographique), $14,3 \%$ et $16,7 \%$ à partir respectivement des valeurs minimales et maximales des moyennes de hauteurs au garrot proposées par F. Audoin-Rouzeau (1991, p. 5) pour « un bétail indigène variant en moyenne de $105 \mathrm{~cm}$ à $115-120 \mathrm{~cm}$, et un bétail importé variant de $120 \mathrm{~cm}$ à 135 - $140 \mathrm{~cm}$ ". 
C. Cornevin, lui aussi professeur à l'École vétérinaire de Lyon : "Lorsque le regard embrasse la série des animaux domestiques, l'action des facteurs autres que la race apparaît sans conteste. L'alimentation se place en première ligne $[\ldots]$ " (Cornevin, 1891, p. 272). Déjà, son accroissement et son enrichissement sont promus par les Agronomes latins qui y attachaient une grande importance (Driesch, 1992). Dans ses Considérations générales sur l'amélioration des races, $\mathrm{H}$. Magne donne un exemple très précis de cette action : " En très peu d'années, le poids moyen des bœufs du Bourbonnais a augmenté de soixante-quinze kilogrammes, par suite de la culture des prairies "(Grognier, Magne, 1841, p. xviij). Aussi, vers 1860, F. Villeroy, cultivateur à Rittershof, met en garde contre le mythe de la nécessaire amélioration raciale par exogamie en attirant l'attention sur la question première du mauvais régime alimentaire : "Quoique j'insiste sur les avantages d'une bonne race déjà établie, je conseille cependant à celui qui en a près de lui une passable, de s'en tenir à celle-là plutôt que d'aller loin en chercher une autre. Souvent des bêtes possèdent de bonnes qualités, dont la misère, le défaut de soins et de nourriture ont seuls arrêté le développement " (Villeroy, ca. 1860, p. 84).

Par ailleurs, l'âge de mise à la reproduction des femelles est également un facteur facile à maîtriser. À la fin du XVIII ${ }^{\mathrm{e}}$ s., l'agronome Rozier, à l'article « Bétail » de son cours complet d'agriculture, expose avec clarté son influence: "Il arrive souvent que des genisses se trouvent pleines à quinze mois, \& même plutôt; \& comme alors elles ont à peine la moitié de leur taille, leur état épuise bientôt les forces qu'elles ont à cet âge ; la mère reste petite \& maigre, elle donne du lait à proportion ; le veau tiendra de sa mère, \& ne sera jamais qu'une bête chétive \& de mauvaise race. Voilà une des principales causes du dépérissement des belles races en France. $\mathrm{Si}$ au contraire les genisses ne sont saillies qu'à deux ans \& demi ; si on leur donne une nourriture convenable, \& en proportion suffisante, on est assuré d'avoir une bête de belle race, \& de remonter \& perfectionner ainsi l'espèce ". De même, un régime alimentaire poussé, appliqué à des mâles castrés dans leur jeune âge, permettra d'obtenir de hauts animaux dont les métatarses demeureront graciles. Ce mécanisme expliquerait avantageusement la présence des grands métatarses graciles entre le $I^{\text {er }} s$. avant J.-C. et le I ${ }^{\text {er }}$ s. après J.-C. Ainsi, la combinaison de ces pratiques - alimentation choisie, âge de mise à la reproduction, âge de la castration - peut expliquer les écarts importants enregistrés entre certains individus et le reste de la population. C'est le cas exposé au milieu du siècle précédent par L.-F. Grognier et par H. Magne $(1841$, p. 85) : « La différence entre la taille est énorme, au midi de la France du moins, entre les vaches et les bœufs; c'est au point qu'on a de la peine à se persuader que des individus, si disparates sous ce rapport, appartiennent à la même race. Il ne faut peutêtre pas chercher les causes de ce phénomène ailleurs que dans l'usage de prodiguer la nourriture aux mâles et de la distribuer aux femelles d'une main avare ".

Ajouté à ces gestes simples, un effort de sélection a pu être porté sur les reproducteurs, afin de retenir des lignées conformées suivant les désirs et besoins des éleveurs. En de multiples régions, certains d'entre eux ont pu transformer leurs animaux plus rapidement et devenir ainsi fournisseurs à plus ou moins longue distance d'un bovin " modifié ", plus grand, acquis par d'autres éleveurs ou par des consommateurs de viandes (villes, armée...). À l'inverse, l'amélioration des bêtes n'a peut-être pas toujours été une priorité comme le constate Francourt (1789, cité par B. Denis, 1997, p. 866) : « Il y a des espèces bien supérieures aux autres ". Mais, de plus, " dans la même espèce et dans le même pays, il y a des sujets infiniment plus beaux que d'autres ». Cela est dû à "la manie qu'ont presque tous les pays d'élève de laisser leurs bestiaux pêle-mêle, de manière que la production s'opère sans aucun choix ". Francourt conseille alors, comme on s'en doute, de ne faire saillir que de " beaux taureaux ". Cependant, il est toujours possible que des éleveurs aient conservé au sein de leur cheptel, pour diverses raisons, des animaux plus petits. C. Guintard cite l'exemple de deux races primitives (Kalmouke et Busa) dont la population présente une forte variabilité due à la présence de "boufs de travail particulièrement bien soignés côtoyant des animaux moins bien entretenus » (Guintard, 1996, p. 156).

Nous n'oublierons pas un facteur sous-jacent à la remarque d'Aristote (Histoire des animaux, III, 21, 20-25) sur la grande taille des animaux d'Épire, notamment les bovins ; « [...] les grands animaux ont besoin de plus de pâture, mais la région possède une telle abondance qu'à chaque saison, il existe des lieux appropriés. " Il est clairement évoqué par O. de Serres (1804-1805, rééd. 1996, p. 414) en association avec la nourriture : « [...] se diversifiant ce bétail-ci [les bovins], et en corpulence, et en 
force, et en pelage, par le climat et la nourriture (comme manifestement telles différences se recognoissent à la bouvine de montagne, à celle de vallon) ". L'environnement naturel des bovins, par ses qualités géographiques, topographiques, géologiques, joue un rôle sur lequel insiste beaucoup C. Cornevin (1891, p. 273) : "En notant la taille des bêtes bovines des pays baignés par la mer du Nord, on voit qu'elle suit des variations en rapport avec la fertilité du sol. Petite sur les terrains granitiques, un peu plus élevée mais chétive encore dans les landes, forte et haute dans les alluvions, elle se calque sur la terre qui la nourrit et en reflète la pauvreté ou la richesse. On peut faire des observations analogues sur le plateau central de la France, dans la région alpestre, en Italie et surtout en Afrique... L'introduction des bêtes shorthorns en Normandie, dans les pâturages très riches en chaux, élève leur taille et amplifie le squelette; celle de bœufs charolais sur le sol granitique du Morvan produit le contraire. La carte géologique d'une région permet de déduire la stature des bøufs et des moutons de ladite région [...]. " L'altitude interviendrait aussi : "Dans un même département dont une partie est basse et l'autre montagneuse, le bétail, quoique de même souche, varie dans son pelage, sa taille, sa conformation, et son faciès change " (Cornevin, 1891, p. 269).

L'action du milieu peut s'exercer avec rapidité comme le souligne l'exemple donné par F. Villeroy qui l'a tiré de la revue Die Holsteinische Milchwirthschaft (ca. 1860, p. 91) : "Après la terrible épizootie de 1769 à 1771 qui enleva presque tout le bétail de la Frise, on fit venir du Jutland des bêtes qui n'étaient comparativement que des nains, qui auraient presque passé sous le ventre des bêtes de l'ancienne race, et sans croisement, dès la troisième ou quatrième génération, elles en avaient atteint l'énorme taille. "Ces constats sont doublement intrigants car s'ils fournissent un argument en faveur de la régionalisation entrevue des morphotypes bovins de la période romaine et $\mathrm{du}$ bas Moyen Âge, et attestée nettement au XVIII' s. (Moriceau, 1999, p. 71, fig. 2), ils vont à l'encontre de l'apparente homogénéité géographique française des morphotypes du II $^{\mathrm{e}} \mathrm{s}$. après J.-C. et ses suivants, du Moyen Âge central, ou encore de La Tène finale (Méniel, 1987, p. 162, fig. 5). Ils fournissent des éléments de réponse à la question de l'existence de races génétiquement fixées avant la révolution agricole. En effet, si la corpulence des bovins est très sensible aux facteurs environnementaux et à l'alimenta- tion, il peut être conclu que les races telles qu'elles sont évoquées dans les textes précédents ne sont pas fixées, c'est-à-dire obtenues par une sélection génétique de la corpulence. Les populations bovines posséderaient alors un potentiel génétique identique sur de vastes régions géographiques, à l'échelle de la France ou plus, dont l'expression morphologique se réaliserait diversement sous les actions combinées, soit synergiques, soit contraires, du milieu et des hommes. Il est évident que l'homogénéité des morphotypes à certaines périodes s'oppose à cette conclusion. Toutefois, bien que les premiers résultats de nos études régionales diachroniques soient peu exploitables car les données sont encore trop disparates (Forest, Rodet-Belarbi, 1998, p. 1034 ), il est possible que l'augmentation du nombre des échantillons nous permette de saisir ultérieurement ces variations morphologiques de terroir. Quoi qu'il en soit, les études archéozoologiques illustreraient le propos de B. Denis (1997) : "L'impact réel des migrations géniques n'a peut-être pas été aussi important qu'on le dit habituellement, au moins pour les périodes anciennes ».

$$
*
$$

L'échantillon de mesures brutes du métatarse disponible à ce jour, mais qui reste encore très insuffisant, permet de mieux cerner l'évolution spatiale et diachronique de la corpulence des bovins entre le $\mathrm{I}^{\mathrm{er}} \mathrm{s}$. avant J.-C. et le XVIII ${ }^{\mathrm{e}} \mathrm{s}$. La population bovine présente durant le siècle et demi qui suit la conquête romaine est proche de la population gauloise, non distinguable ostéométriquement par les métatarses. Les animaux de plus grande corpulence résultent d'une production d'individus spécialisés - bœufs, taureaux - issus du cheptel indigène. Ce dernier se transforme au cours du II ${ }^{\mathrm{c}} \mathrm{s}$. après J.-C., au profit d'une population bovine composée de bêtes plus grandes et probablement plus fortes. Néanmoins, l'ostéométrie du métatarse ne peut séparer, avec certitude, ce type morphologique de la population précédente. Une meilleure gestion " zootechnique ", développée pendant cent à cent cinquante ans à partir de la conquête, explique, à notre avis, cette modification de la corpulence des animaux. L'ensemble des ouvrages agronomiques et vétérinaires consultés, qui vont de la fin du $\mathrm{XVI}^{\mathrm{e}} \mathrm{s}$. à la fin du XIX ${ }^{\mathrm{e}} \mathrm{s}$, insistent d'ailleurs sur l'importance du nourrissage pour un bon développement physique des animaux. L'hypothèse d'une importation, 
bien qu'elle ne puisse être totalement exclue, n'est pas nécessaire à l'explication des évolutions ostéométriques du métatarse, d'autant que l'absence de travaux sur la morphologie des bovins de la péninsule Italique nous prive d'un référentiel indispensable pour pouvoir comparer les animaux romains importés aux animaux gaulois et gallo-romains. La notion de " grand bouf " gallo-romain ne peut être appliquée qu'à la période allant du II" s. après J.-C. au VI"s., voire VII" s. après J.-C., les grands bovins des siècles précédents n'étant que des individus extrêmes dans la population gauloise. La modification de la corpulence des bovins en Gaule n'est pas une " romanisation " immédiatement consécutive à la conquête, mais semble plutôt être la conséquence d'une transformation de l'élevage bovin, au moins galloromain, sous l'effet d'une modification socio-économique du monde agricole qu'auraient pu induire les ajustements structurels de l'Empire durant la seconde moitié du I I ${ }^{\mathrm{cr}} \mathrm{s}$. après J.-C. La corpulence se réduit entre le VII $^{c}$ et le VIII"s. Au IX"s., les animaux atteignent une corpulence minimale qu'ils conservent durant quatre siècles. Cette lente diminution de corpulence n'affecte pas leur robustesse ; à aucune période chronologique, on ne retrouve la gracilité des bovins de La Tène. Plus qu'à une perte brutale des connaissances zootechniques résultant des invasions et de l'instabilité politique, elle est peut-être due à un choix, une gestion différente liée à des habitudes ou des besoins autres. Puis, la corpulence des animaux augmente de nouveau, probablement au cours du XIII ${ }^{c}$ s. ${ }^{19}$, et sûrement au cours du XIV ${ }^{e}$ s. Ils acquièrent une corpulence qu'ils garderont aux $\mathrm{XVI}^{\mathrm{c}}$ et XVII's. Les corpulences les plus grandes de l'Antiquité tardive ne reparaissent à nouveau qu'à partir de la fin du XVIII" s. (Cornevin, 1891, p. 106), mais nous n'en possédons aucune trace archéologique, d'où l'intérêt de ne pas rejeter systématiquement des mobiliers osseux en contextes archéologiques bien datés du XIX" s., voire du début du XX"s.

$\grave{A}$ aucun moment de cette longue séquence chronologique il n'existe deux ou plusieurs populations parfaitement différenciées par une répartition bimodale ou plurimodale des mesures des métatarses, ou par des

19. Une étude récente nous laisse entrevoir qu'en Languedoc les prémices d'une évolution se manifesteraient dès la première moitié du XIII"s., le siècle de l'apogée de l'extension des terres céréalières et de l'expansion démographique. variabilités maximales excessives. Ceci se traduit par un " noyau " commun à toutes les périodes, composé des valeurs " moyennes ", auquel s'associent suivant les périodes soit les " petites " valeurs, soit les " grandes » et "très grandes" valeurs. Ainsi, la variation moyenne de longueur entre les populations métatarsiennes extrêmes et chronologiquement séparées s'approche de $15 \%$.

Ce travail, fondé exclusivement sur les mesures brutes du métatarse, prend en compte aussi bien la longueur de l'os que ses largeurs. Il est ainsi possible d'aborder la question de la corpulence de l'animal, sans se limiter à sa seule hauteur. En outre, les données métriques collectées ont été disposées dans les tableaux selon la datation du niveau archéologique d'où est issu l'os considéré. Cette vision diachronique permet de suivre avec acuité les modifications observées au cours des siècles. Enfin, les tableaux que nous présentons constituent un cadre référentiel, de La Tène finale au XVIII ${ }^{\mathrm{e}}$ s., dans lesquels tout chercheur peut désormais replacer les données métriques d'un métatarse et, par là, en déduire approximativement la corpulence relative de l'animal considéré. Les désignations qualitatives " petit ", « moyen "... sont ainsi clairement attachées à des repères métriques. Enfin, ces tableaux fournissent, certes de manière encore frustre, des points de comparaison régionaux et chronologiques pour la France, qui sont mis à la disposition de tous.

L'étude du métatarse seul s'avère insuffisante. En effet, les rapports entre les segments osseux des membres diffèrent entre " petit bouf " et " grand bœuf " (Brunaux, Méniel, 1983). L'étude des divers os découverts dans des niveaux archéologiques médiévaux ou modernes a montré des écarts entre différents organes (Forest, Rodet-Belarbi, 2000). Par exemple, en période médiévale, dans l'articulation du coude, l'extrémité distale de l'humérus et l'extrémité proximale du radius, qui s'affrontent, ont des largeurs qui n'évoluent pas tout à fait de concert. De même, dans le jarret, la largeur de l'extrémité distale du tibia livre une courbe plus homogène que celles des largeurs de l'extrémité proximale du métatarse et de l'extrémité distale du talus. Une augmentation du corpus permettra d'affiner cette perception.

L'enregistrement des valeurs ostéométriques de longueur et de largeurs doit se poursuivre pour enrichir une base de données encore trop faible pour certaines périodes et/ou certaines régions. Puis, il sera nécessaire 
de décrypter les processus des modifications observées à l'aide des lois biologiques et zootechniques qui régissent l'espèce bovine et ses sous-populations, ce qui amènera à réfléchir sur la notion génétique de race, et de tenir compte de la nature des contextes archéologiques pour identifier les biais introduits par l'homme lors de ses choix d'animaux. Une fois ces étapes franchies, les phénomènes socio-économiques sous-jacents aux modifications de la corpulence des bovins de la conquête romaine au XVIII' s. pourront être abordés avec plus d'assurance. On peut se demander, en effet, dans quelle mesure ces variations de corpulence des bovins sont le fruit d'une volonté des éleveurs pour obtenir un type d'animal parfaitement inséré dans l'organisation socioéconomique ou si, au contraire, elles sont la conséquence de cette même organisation, reçue passivement par les éleveurs au fil du temps sans qu'ils en aient pleinement conscience. 


\section{BIBLIOGRAPHIE}

AI.FONSO G., FOREST V.

1998 : Aigueperse (Puy-de-I)ôme), Les Cérais. Habitat rural du haut Moyen Âge. Nécropole de l'âge du Fer; Document final de synthèse, AFAN, Service régional de l'archéologie Auvergne, ClermontFerrand, 3 vol.

Allain J., Cothenet A., PoulainJOSIEN T., VAUTHEY M.

1966 : «Un dépotoir augustéen à Argentomagus (Saint-Marcel, Indre) ", Revue archéologique du Centre de la France, V, p. 17-39.

Ai.lain J., Fifuriot L., Chaix L.

1981 : « Le Vergobret des Bituriges à Argentomagus, essai d'interprétation d'une fosse cultuelle ", Revue archéologique de l'Est et du Centre-Est, XXXII, p. 11-32.

\section{ARISTOTE}

1994 : Histoire des animaux, trad. J. Bertier, Paris, Gallimard, coll. Folio essais, $590 \mathrm{p}$.

Ariaud C., Burnouf J., Bravard J.-P., ARbo(iast R.-M.

1994 : Lyon Saint-Jean. Les fouilles de lîlot Tramassac, Documents d'archéologie en Rhône-Alpes, 10, 4, p. 117-133.

ARIAUD C., Forest V.

1995 : Fonilles archéologiques de la Place des Terreaux, Lyon 1991-1994, Document final de synthèse, AFAN, Service régional de l'archéologie RhôneAlpes, Lyon, p. 423-447.

ARI AUd C., Lurol. J.-M., Forrst V. 1990 : Chantier archéologique. Place de la Bourse, Lyon, Document final de synthèse, AFAN, Service régional de l'archéologie Rhône-Alpes, Lyon, p. 162-186.

1992 : Chantier archéologique. Place de la République, Iyon 1991-1992, Document final de synthèse, AFAN, Service régional de l'archéologie RhôneAlpes, Lyon, p. $147-148$ et p. 319-330.
1993 : Fouilles archéologiques de la Place des Célestins à Lyon 1992-1993, Document final de synthèse, AFAN, Service régional de l'archéologie RhôneAlpes, Lyon, p. 336-352.

ARRAMOND J.-C., BOUdARTCIOUK J.-L., Grimbikt I., Llich L., MOIFT H., Le. Nohet C., Reverdy S., RodetBEIARBI I.

1993 : Parking Esquirol, Toulouse (HauteGaronne), Document final de synthèse, AFAN, Service régional de l'archéologie Midi-Pyrénées, Toulouse, p. $1-25$.

\section{AudoIn-Rouzeac F.}

1986 : Ossements animaux du Moyen Âge au monastère de la Charité-sur-Loire, univ. de Paris 1-Panthéon-Sorbonne, Histoire ancienne et médiévale, 18, Publications de la Sorbonne, $166 \mathrm{p}$.

1991 : La taille du bouf domestique en Europe de l'Antiquité aux Temps Modernes, Fiches d'ostéologie animale pour l'archéologie, Mammifères, 2, Paris, CNRS-CRA, éd. APDCA, $40 \mathrm{p}$.

1993 : Hommes et animaux en Furope, corpus de données archéozoologiques et historiques, Dossier de documentation archéologique, 16, Paris, CNRS Éditions, 527 p.

1995 : “Compter et mesurer les os animaux. Pour une histoire de l'élevage et de l'alimentation en Europe de l'Antiquité aux Temps Modernes ", Histoire el Mesures, X, 3/4, p. 277-312.

1997a: "Cheptel antique, cheptel médiéval : mutations ou innovations? ", in BECK P. (dir.), Linnovation technique au Moyen Âge, Actes du $\mathrm{VI}^{\mathrm{c}}$ congrès international d'archéologie médiévale Archéologie d'aujourd'hui, Paris, éd. Errance, p. 30-34.

1997b: "Les éléments nouveaux de l'élevage aux Temps Modernes ", in Baratay E., MaYaUd J.-L. (dir.),
L'animal domestique, $X V T^{p}-X X^{e}$ siècle, Cahiers d'histoire, XI.II, 3-4, p. 481-509.

AuxistTt: $\mathrm{G}$.

1994 : Mille ans d'occupation humaine. Mille ans d'élevage. L'exploitation des animaux sur les sites du Bronze final ì l'Augustéen dans la vallée de l'Aisne, thèse de doctorat nouveau régime, univ. de Paris 1-Panthéon-Sorbonne, 3 vol.

Barberan S., Bel. V., IIervé M.-L., Leilí̀vre V., Maufras O., Amandry M., Borgard P., Cammas C., Cheviliot P., Darde D., Ippolito F., Montell, M., Potay C., RodetBEI ARBI I.

1998 : Occupations antique et médiévale en périphérie de l'agglomération nimoise, ZAC du forum des Carmes à Nimes (Gard), Document final de synthèse, AFAN, Service régional de l'archéologie Languedoc-Roussillon, Montpellier.

BARONE R.

1976 : Anatomie comparée des Mammiferes, 1, Paris, Vigot.

Barrai. P., Joly M., Roditt-Blilarbi I.

1993 : « Nouvelles données sur l'occupation précoce de Langres ", Bulletin de la Sociélé archéologique champenoise, 86, p. $49-81$.

BARTOSIEWIC: L., VAN Nier W., LeNTACKl:R A.

1997 : Draught caltle : their osteological identification and history, Annales sciences zoologiques, 281, Musée royal de l'Afrique centrale, Tervuren, $147 \mathrm{p}$.

BÉAL. J.-C., RODET-BHI ARBI I.

1997-1998: "Lyon (69), $2^{c}$ arrond. découverte $n^{\circ}$ 2-41 ", in L'artisanat dans les villes antiques, PCR sous la dir. de J.-C. Béal, p. 66-67. 
BÉkATO J., BORREANI M., I.Eglit.l OLX M. 1990 : " La villa gallo-romaine des Laurons (quartier Saint-Pierre), Les Arcs-sur-Argens ", Documents d'archéologie méridionale, 13, p. 221-247.

Bergeret J.-L., Aurand C., Bioli. C., ROIDET-BELARBI I.

1998 : Archéologie el tramway - Diagnostic 6 Boulevards L.-Blanc et L.-Pasteur. Montpellier, Hérault (34), Document final de synthèse, AFAN, Service régional de l'archéologie Languedoc-Roussillon, Montpellier, 133 p. et annexes.

BERMONI I., FOREST V.

1996-1997: Quarunle, Soulomiac. Bâtimem el zone d'ensilage en périphérie d'un habilat gallo-romain et médiéval: études archéologiques sur le tracé du Gazoduc Artère du Midi, vol. 9: secteur du NordBiterrois, Document final de synthèse, AFAN, GDF, Service régional de l'archéologie Languedoc-Roussillon, Montpellier, $69 \mathrm{p}$.

BHLLAUT N.

1997 : Les vestiges fauniques de Notre-Damede-Pinel (XIT-XVII siècles) en HauteGaronne, thèse pour le doctorat vétérinaire, École nationale vétérinaire de Toulouse, $113 \mathrm{p}$.

BoIRON R., GARIDEISEN A.

1993 : Salignac, la Vallée (Alpes-de-HauteProvence), Document final de synthèse, AFAN, Service régional de l'archéologie Provence-Alpes-Côte d'Azur, Aix-en-Provence.

Boudaktchouck J.-L., Gardes P., Molet H., Abil a R., Rodet-Belarbi I. 1995 : A-64 Landorthe "Le Castéra", Document final de synthèse, AFAN, Service régional de l'archéologie Midi-Pyrénées, Toulouse, 2 rol.

Boliter A., Faure-Bolchiari.at E., MoNitik J., Forrst V., LAFFONT P.-Y. 1992 : " La motte castrale de DécinesCharpieu (Rhône) ", Archéologie médiéuale, XXII, p. 268-276.
Bolviter A., Forest V.

1993 : Simandres, la Plaine. Contournement autoroutier est de Lyon. Autoroute A46. Zone sud, Document final de synthèse, AFAN, Service régional de l'archéologie Rhône-Alpes, Lyon.

Brunaux J.-L., Méniel. P.

1983 : "L'importation du bœuf à la période romaine: premières données, les fouilles de Gournay-surAronde ", Revue archéologique de Picardie, 4, p. 15-20.

CaRANDini A. (DIR.)

1985 : Selte Finestre, Modène, ed. Panini, $3 \mathrm{vol}$.

Carrìre I., Forest V.

À paraître : "Les bovins du Néolithique moyen au Bronze ancien en Languedoc : éléments de réflcxion ", in Actes des 4 rencontres méridionales de Préhistoire récente, Nîmes, 28-29 oct. 2000.

Carríke: I., Forest V., Rodet-Bliakbi I.

A paraitre: "Osteometry and shifts in the bovine population in France ", in GaRdeISEN A. (dir.), Mouvements et déplacements de populations animales en Médilerranée au cours de l'Holocène. Actes du séminaire de recherche, Iattes, sept. 2000, British Archaeological Report.

Catalo J., Chiabrando M., Filhol. C., Gentilève V., Ribiero J., Rifa P., RODET-BELARBI I.

1995 : Hôtel d'Assézat $/ n^{\circ} 4$ rue ClémenceIsaure, Toulouse, Document final de synthèse, AFAN, Service régional de l'archéologie Midi-Pyrénées, Toulouse, 2 vol.

Cataio J., I.f.ch I., Ribifro J., Rifa P., RODFT-BEI ARBI I.

1995 : Extension-Préfecture, rue Sainte-Anne, Toulouse (Haute-Garonne), Document final de synthèse, AFAN, Service régional de l'archéologic MidiPyrénées, Toulouse, 2 vol.

CATAlO J., Ll.E.H L., RODFT-BEI ARBI I. 1996 : Donjon du Capitole, Toulouse, Document final de synthèse, AFAN,
Service régional de l'archéologie Midi-Pyrénées, Toulouse.

CAzES Q., Gardair V., BotdidTChOLCK J.-L., Casanave. S., Perron D'Arc: $M$.

1989 : «Les fouilles du Rectorat à Toulouse ", Mémoires de la Société archéologique du Midi de la France, XILIX, p. 7-43.

Chaix L.

1980 : « La faune du vicus gallo-romain de Lousonna-Vidy (Vaud-Suisse) (fin du I'r s. av. J.-C./milieu du III's. apr. J.-C.) ", Cahiers d'archéologie romande, 18,2 , p. 168-193.

1984 : "Note sur un aurochs (Bos primigenius Bojanus) subatlantique du Jura gessien (Ain, France) ", Revue de paléobiologie, 3, 2, p. 185-190.

Cinax I., Mŕnili. P.

1996 : Éléments d'archéozoologie, Paris, éd. Errance, $112 \mathrm{p}$.

Chardron-Picault P., Pernot M., Alfonso G., Boyer F., Creusenet F., Duckelx F., Groftembril. S., Haut P., Olmir F., Plogun A., Popovtrch L., RENEI, F., RODET-BELARBI I., SERniels V., SOLARI M.-E., VAXFI AIRE L.

1999 : Un quartier antique d'artisanat métallurgique ì Autun, le site du Lycée. mililaire, Document d'archéologie française, archéologie préventive, 76 , p. 293-301.

Colardeilie M., Verdei. E., Oi.ne C. 1993 : "La faune terrestre ", in Charavines, les habitants du lac Palladru (Isère) dans leur environnement. I.a fondation d'un terroir au XI s., Document d'archéologie française, 40 , p. $98-115$.

Col.umeau P.

1985 : La chasse et l'élevage en Gaule méridionale d'après les vestiges osseux, thèsc de doctorat d'État, univ. de Provence, Aix-en-Provence.

CONGès G., Lecinholx M., BRILNPortevin $F$.

1991 : “ Un dépotoir de l'Antiquité 
tardive dans le quartier de l'Esplanade à Arles ", Reoue archéologique de Narbonnaise, 24, p. 226-287.

COQUIDÉ C., Forest V.

1994 : Contournement sud de Meyzieu. I.a Chapelle-Meyzieu (69), Document final de synthèse, AFAN, Service régional de l'archéologie Rhône-Alpes, Lyon.

Cornevin C.

1891 : Traité de zootechnie générale, Paris, Librairie J.-B. Baillière et Fils, 1088 p.

DeNIS B.

1997 : " Des sources d'étude des races d'animaux domestiques en France avant le $19^{\circ}$ siècle ", Revue de médecine vétérinaire, 148-11, p. 861-872.

\section{DotTrens E.}

1946 : «Étude préliminaire: les phalanges osseuses de Bos Taurus domesticus ", in Revill.IOD P., DotTrens E. (dir.), La faune néolithique de la couche profonde de Saint-Aubin, Revue suisse de zoologie, 53,33 , p. $739-775$.

DRIESCH A. VON DEN

1976 : A guide to the measurement of animal bones from archaeological sites, Peabody Museum Bulletin, 1, 137 p.

1992 : «L'élevage des animaux domestiques dans les cultures européennes pré- et protohistoriques ", Revue de médecine vétérinaire, 143-2, p. 113-137.

DRIFSCH A. VON DEN, BOESSNECK J.

1974 : Kritische Anmerkung zur Widerristhöhenberechnung aus Längenmassen vor- und frühgeschichtlicher Tierknochen, Säugetierkundliche Mitteilungen, 22, p. 325-348.

DUMASy F., BOUChaIN I., RODET-BEl aRBI I. 1996 : La fouille de la voie Est-Ouest à Argentomagus-Saint-Marcel (Indre), Document final de synthèse, AFAN, Service régional de l'archéologie Centre, Orléans.

Favory F., Raynaui) C., Forest V.

1993 : " Archéologie gallo-romaine et médiévale à Lunel-Viel (Hérault) ", in Autour de l'étang de l'Or : espace rural et habitat dans le Montpelliérais à l'époque romaine et au Moyen Âge, Rapport de synthèse, CNRS, ATP, SDA, programme H11, $451 \mathrm{p}$.

Fiches J.-L., Col.umeau P.

1989 : L'oppidum d'Ambrussum el son territoire. Fouilles au quartier du Sablas (Villetelle, Hérault) : 1979-1985, Paris, éd. du CNRS, coll. Monographie du CRA, 2, p. 209-227.

FOREST V.

1987 : Vestiges fauniques ossenx $d u X I^{r}$ au $X I V^{p}$ s. en Rhône-Alpes, thèse pour le doctorat vétérinaire, École nationale vétérinaire de Lyon, $103 \mathrm{p}$.

1992 : «Archéozoologie des sites de Lastours, Durfort et Villeneuve-laComptal ", in Formes et fonctions de l'habitat castral en France méridionale. Les apports de la bordure méridionale du Massif central, Rapport triennal de synthèse, Projet collectif $01 \mathrm{du}$ programme H18 du CSRA «Villages et terroirs médiévaux et postmédiévaux », p. 128-150.

1997 : «Données biologiques et données zootechniques anciennes. Essai de mise en équivalence ", Revue de médecine vétérinaire, 148-12, p. 951-958.

1998a: Saint-Paul-Trois-Châteaux, époques gallo-romaine et médiévale, Rapport d'étude archéozoologique, Mairie de Saint-Paul-Trois-Châteaux.

1998b : " De la hauteur au garrot chez les espèces domestiques ", Rezue de médecine vétérinaire, 149-1, p. 55-60.

À paraître : "Étude archéozoologique ", in SABritr R. (dir.), le clos de la Lombarde, Narbonne (Aude) (75 av. J.-(..425 apr. J.-(.), Revue archéologique. de Narbonnaise.

FOREST V., RODET-BEILARBI I.

1997 : " Augmentation du format des bovins en Gaule romaine : problèmes méthodologiques et innovations techniques ", in Garcia D., Mrek D. (dir.), Techniques et économie antiques et médiévales, le temps de l'innovation, Actes du colloque d'Aix-en-Provence, mai 1996, Paris, éd. Errance, p. 166-171.

1998 : «Ostéométrie du métatarse des bovins en Gaule, de la Conquête romaine à l'Antiquité tardive ", Revue de médecine vétérinaire, 149-11, p. $1033-1056$.

2000 : «Ostéométrie et morphologie des bovins médiévaux et modernes en France méridionale ", in MARANDET M.-C. (dir.), Lhomme et l'animal dans les sociétés méditerranéennes, 4" Journée d'études du Centre de recherches historiques sur les sociétés méditerranéennes et du pôle universitaire européen de Montpellier et du LanguedocRoussillon, Perpignan, univ. de Perpignan, Presses universitaires de Perpignan, p. 27-91.

FOUET G. (DIR.)

1983 : La villa gallo-romaine de Montmaurin (Haute-Garonne), XX' Suppl. à Gallia, Paris, éd. du CNRS, 392 p., 157 fig., LXXI pl.

Foukt G., Labrousse M., PoulainJosien T., Jaceuiot C., LEMONNIER M.A.

1958 : «Puits funéraires d'Aquitaine : Vieille-Toulouse et Montmaurin ", Gallia, XVI, 1, p. 115-196.

GARIDEISEN A.

1993 : “État de l'élevage dans le haut Moyen Âge camarguais et en milieu lagunaire ", in L'homme, l'animal domestique et l'environnement du Moyen Âge au XVIII s., Centre de recherches sur l'histoire du Monde atlantique, Nantes, Ouest éditions, 19, p. 141-162.

Garifi. M.-E., Al. abert B., Al.labert S., Barat M.-C., Barrère M., Bès C., BouAs F., BOUdDaRTCHOUCK J.-L., CORneit L., Dir.ulafatt F., Forfst V., Fortinfant F., Gardel. G., Gau M., GaU J.-B., Jaudon B., Joucia J.-L., Olivier S., Ruas M.-P., Satgế P., TOLLON F.

1999 : Cabaret : histoire et archéologie d'un castrum, les fouilles du site médiéval de Cabaret à Lastours, Aude, Carcassonne, CVPM-Maison des Mémoires, 500 p. 
Gautier A.

1972 : « La faune d'un puits de l'abbaye de Saint-Avit-Senieur $\left(\mathrm{XI}^{\circ} \quad\right.$ à XII" siècle, Dordogne, France) ", Archéologie médiévale, II, p. 356-379.

Ginouvez O., Forest V.

1997-1999: Faculté de Droit. Montpellier. Hérault. Bas Moyen Âge, Document final de synthèse, AFAN, Service régional de l'archéologie Languedoc-Roussillon, Montpellier.

Ginouve7, O., Gardeisen A.

1996 : Fouilles de l'Hôtel-Dieu à Narbonne. (Hérault), Document final de synthèse, AFAN, Service régional de l'archéologie Languedoc-Roussillon, Montpellier.

Goguey R., REDdÉ M., LePETZ S. 1995 : Le camp légionnaire de Mirebeau, Mainz, Verlag des RömischGermanischen Zentralmuseums in Kommission bei Dr Rudolf Habelt GMBH Bonn, p. 359-370.

Grenouli.louX A.

1989 : L'élevage bovin dans le haut Moyen Âge occidental, thèse pour le doctorat vétérinaire, École nationale vétérinaire de Nantes.

Grognier L.-F., Magne H.

1841 : Cours de multiplication et de perfectionnement des principaux animaux domestiques, $3^{e}$ éd. revue et augmentée par H. Magne, Paris-Lyon, 709 p.

Guil.hot J.-O., Goy C., MÉNiei. P. 1992 : « À boire et à manger. Trahi par sa poubelle ", in Les fouilles du parking de la mairie de Besançon, Besançon, musée des Beaux-Arts et d'Archéologie, p. 174-187.

Guintard C.

1996 : Étude ostéométrique des métapodes de bovins: la race charolaise, thèse de doctorat, Muséum national d'histoire naturelle, 2 vol.

1997 : «Identifier et mesurer l'évolution de l'élevage bovin : un problème de méthode en archéozoologie ", in BECK P. (dir.), L'innovation technique au Moyen Âge, Actes du VI congrès international d'archéologie médiévale, Paris, éd. Errance, p. 21-31.

1998 : "Ostéométrie des métapodes de bovins ", Revue de médecine vétérinaire, 149-7, p. 751-770.

Horard-Herbin M.-P., Méniel P., SÉguier J.-M.

2000 : "La faune de dix sites ruraux de la fin de l'âge du Fer de la Bassée (Seine-et-Marne) ", in Les installations agricoles de l'âge du Fer en France septentrionale, Études d'histoire et d'archéologie, 6, Paris, éd. rue d'Ulm, p. 181-208.

Jandot C., Barberan S., Forest V., RODET-BELARBI I.

1998-1999 : Saint-Jean-d'Aureilhan, Zac Montimaran, Document final de synthèse, AFAN, Service régional de l'archéologie Languedoc-Roussillon, Montpellier.

JOURDAN L.

1976: La faune du site gallo-romain et paléochrétien de la Bourse (Marseille), Paris, éd. du CNRS, 338 p.

KRAEMER H.

1900 : " Die Hausteirfunde von Vindonissa ", Revue suisse de zooloogie, 7, p. 143.

KraUSZ S.

1985 : Les ossements animaux du village des Arènes à Leoroux (Indre) : le terrain Lacotte. Contribution à l'étude de la faune à La Tène finale, mém. de maîtrise, univ. de Paris 1-PanthéonSorbonne.

Latour L., Poulain-Josien T.

1970 : “ Les fouilles gallo-romaines d'Auterive (Haute-Garonne) ", Mémoires de la Société archéologique du Midi de la France, XXXV, p. 9-69.

LEGUil.I.OUX M.

1994 : L'archéozoologie et l'interprétation des sites. Recherches archéozoologiques sur la Provence romaine et médiévale, thèse de doctorat nouveau régime, univ. de Provence, Aix-en-Provence.

\section{LEPETZ S.}

1991 : « Les restes animaux des fouilles de l'Hôtel-Dieu à Beauvais (Oise) ", Rerue archéologique de Picardie, 3, 4, p. 273-292.

1995a: L'animal dans la société galloromaine de la France du Nord, thèse de doctorat nouveau régime, univ. de Paris 1-Panthéon-Sorbonne, 2 vol.

1995b : “ L'amélioration des races à l'époque gallo-romaine: l'exemple du bœuf ", in Homme et animal dans l'Antiquité romaine, Actes du colloque de Nantes 1991, $\mathrm{n}^{\circ}$ hors série de Caesarodunum, Tours, p. 67-78.

1996 : "Effets de la romanisation sur l'élevage dans les établissements ruraux du nord de la Gaule. L'exemple de l'augmentation de la stature des animaux domestiques ", Revue archéologique de Picardie, $\mathrm{n}^{\circ}$ spécial 11, p. 317-324.

LePETZ S., YVinec; J.-H., Desse-Berset N. 1998 : «L'élevage à la période galloromaine et au haut Moyen Âge en Normandie. L'apport de l'archéozoologie ", in Le monde rural en Normandie, Annales de Normandie, série des Congrès des sociétés historiques et archéologiques de Normandie, vol. 3, p. 83-109.

Lignerfux Y., Garic: R., Columeau Ph. 1994 : " Analyse ostéoarchéologique d'une fosse à offrande gallo-romaine de Rodez (Aveyron) ", Revue de médecine vétérinaire, 145-11, p. $839-856$.

\section{LignereuX Y., PETERS J.}

1997a : «Viandes, volaille et fruits de mer à la table des légions romaines d'Aunedonnacum, 20-30 apr. J.-C. (Aulnay-de-Saintonge, CharenteMaritime) ", Revue de médecine vétérinaire, 148-4, p. 277-298.

1997b : "Viandes, volaille et fruits de mer à la table des légions romaines d'Aunedonnacum, 20-30 apr. J.-C. (Aulnay-de-Saintonge, CharenteMaritime) ", Revue de médecine vétérinaire, 148-5, p. 399-412.

MAR(HAND G.

1979 : Inventaire des restes osseux provenant 
du sile archéologique gallo-romain de la "villa d'Éros" dans le Vexin fransais, thèse pour le doctorat vétérinaire, École nationale vétérinaire de Maisons-Alfort, $68 \mathrm{p}$.

Martin J.-M., Gangiofo N.

1994 : Une occupation antique sur une pente aménagée, Rodez, 13 bld d'Estourmel (Aveyron), Document final de synthese, AFAN, Service régional de l'archéologie Midi-Pyrénées, Toulouse.

MARTIN L., Foress V.

1996 : Moulines. Lansargues (Hérault). Habitat et cimetière du Moyen Âge $\left(V I I I^{e} / X I V^{e}\right.$ s.), Document final de synthèse, AFAN, Service régional de l'archéologie Languedoc-Roussillon, Montpellier.

Matol.si J.

1970 : “ Historische Erforschung der Körpergrösse des Rindes auf Grund von ungarischen Knochenmaterial ", Yeitschrift für Tierzüchtung und Züchtungsbiologie, 87, p. 89-137.

MAUNÉ S., Forest V.

1995 : La villa gallo-romaine de Lieussac (Montagnac, Hérault), Document final de synthèse, AFAN, Service régional de l'archéologie Languedoc-Roussillon, Montpellier.

1997 : Puissalicon-Les Juriërres Basses (Héraull). Haut-Empire - Antiquité tardive, Document final de synthèse, AFAN, Service régional de l'archéologie Languedoc-Roussillon, Montpellier.

Míniti P.

1987 : «L'élevage en Gaule. Les structures de l'élevage en France septentrionale à la fin de l'âge du Fer ", Archaeozoologia, 12, p. 149-166.

1989 : “Les restes animaux du château de "la Cologne" à Hargicourt (Aisne) (XIV"-XV' siècles) ", Revue archéologique de Picardie, 3-4, p. 193-202.

1993 : "Les restes animaux des fosses et des puits du site gallo-romain de Bliesbruck (Moselle) ", Blesa, 1, Publication du parc archéologique européen, éd. Serpenoise, p. 91-105.
Méniti. P., Chaix L.

1996 : Eléments d'archéozoologie, Paris, éd. Errance, $112 \mathrm{p}$.

Mtrciler F., RoDEt-BEIARBI I.

1989 : Fouilles sur le site " Cl. (happe II" au Mans (Sarthe), Document final de synthèse, AFAN, Service régional de l'archéologie Pays de la Loire, Nantes.

Mitard P.-H., Berthier G., Hofmann B., Jobli.ot N., Poulain-Josien T.

1993 : "Les ossements recueillis dans les "foyers B et D" du temple galloromain de Genainville (Val-d'Oise) ", in I.e sanctuaire gallo-romain de Genainville (Val-d'Oise), Centre de recherches archéologiques du Vexin français, Guiry-en-Vexin, p. 411-413.

MONTFil. M., GaRdeisten F.

1993 : “ Les fouilles de la ZAC des Halles à Nîmes (Gard) ", in L'alimentation carnée à Nîmes (entre 150 av. J.-C. el 400) apr. J.-C.), Suppl. 1 au Bulletin de l'École antique de Nîmes, p. 245-257.

MoRfi. C.

1985 : Inventaire des restes osseux provenant du site archéologique moyenâgeux de Saint-Denis. Contribution ì l'étude de l'alimentation de l'homme, thèse pour le doctorat vétérinaire, École nationale vétérinaire de Maisons-Alfort.

MORICEAU J.-M.

1999 : Les fondements agraires de la France. moderne (XVI-XVIII siècles). L'élevage sous l'Ancien Régime, Regards sur l'histoire, éd. Storss, $256 \mathrm{p}$.

MY N.

1993 : Les ossements animaux du macellum gallo-romain de Saint-Bertrand-deComminges, le boouf et le cerf, thèse pour le doctorat vétérinaire, École nationale vétérinaire de Toulouse, $98 \mathrm{p}$.

Pascatini M., Landure C., Forest V.

À paraître: Della du Rhône, synthèse des études archéozoologiques (Antiquité-Moyen Âge), PCR.
Passeiac: M., Gardeisen A.

1995 : Bram, Rapport de fouilles programmées, 1995, Service régional de l'archéologie Languedoc-Rousillon, Montpellier.

Prinon J., Pirnon C., Oline C.

1990 : « Les potiers de Portout. Productions, activités et cadre de vie d'un atelier au Ve siècle apr. J.-C. en Savoie ", in Portout: premières données sur l'élevage en Savoie au V" siècle, 20" Suppl. à la Revue archéologique de Narbonnaise, Paris, éd. du CNRS, p. 36-53.

Personnaz B.

1992 : Les ossements animaux du sile de la place Saint Étienne à Toulouse : le puits public (XVI'-XVII s.), thèse pour le doctorat vétérinaire, École nationale vétérinaire de Toulouse, $247 \mathrm{p}$.

\section{PETERS J.}

1998 : Römische Tierhaltung und Tierzucht. Eine Synthese aus archäozoologischer Untersuchung und schriftlich-bildlicher Überlieferung, Passauer Universitätschriften zur Archaölogie, 5, Rahden, Verlag Marie Leidorf GmbH \& Co., $444 \mathrm{p}$.

Peyre G., Abil a R., Roteit-Beilarbi I. 1993 : Chantier archéologique "Paul Féuga" ('Toulouse), Document final de synthèse, AFAN, Service régional de l'archéologie Midi-Pyrénées, Toulouse.

Phil.IPPOT A.-G.

1992 : Contribution archéozoologique à linlerprétation du site gallo-romain de Meulan-Les Mureaux (Yvelines), mém. de maîtrise, univ. de Paris 1Panthéon-Sorbonne.

Piponniler F., Alitxandore-Bid)on D., BrockBossird C., CARCEI. A., Gourgouse Y., Maccari-Poisson B., POISSON J.-M.

1993 : Le Château d'Essertines -6- Les vestiges osseux, Documents d'archéologie en Rhône-Alpes, 8, p. 119-128.

Pomarèdes H., Gardeisen A.

1994 : Saint-André-de-Codols, Nîmes 
(Gard), Document final de synthèse, AFAN, Service régional de l'archéologie Languedoc-Roussillon, Montpellier.

POULAIN-JOSIEN T.

1965-1966: «Étude de la faune provenant d'un habitat gallo-romain du IV" siècle aux Fontaines-Salées à Foissy-sous-Vézelay (Yonne) ", Bulletin de la Société des sciences historiques et naturelles de l'Yonne, 101, p. 201-203.

Poul. M., Rodet-Bei_arbi I.

1989 : Fonilles sur le site "Étoile-Jacobins" au Mans (Sarthe), Document final de synthèse, Service régional de l'archéologie Pays de la Loire, Nantes.

\section{RAFPSAET G.}

1995 : «L'utilisation animale dans les transports antiques. Récents développements. Nouveaux problèmes ", in Homme et animal dans l'Antiquité romaine, Actes du colloque de Nantes, 1991, n hors série de Cicesarodunum, univ. de Tours, p. 324-326.

\section{REVILLIOD P.}

1926a : "Sur les animaux domestiques de la station de l'époque de La Tène de Genève et le bœuf brachycéphale de l'époque romaine ", Archives des Sciences physiques et naturelles, 8, p. $65-74$.

1926b: "Habitation gauloise sur l'oppidum de Genève: les animaux domestiques ", Geneva, IV, p. 111-118.

\section{RIFIDEI. A.}

1986 : " Risultati di ricerche archeozoologiche eseguite nella regione fra la costa adriatica ed il crinale alpino (dal Neolitico recente al Medio Evo)/Archäozoologische Untersuchungen im Raum zwichen Adriaküste und Alpenhauptkamm ", Padusa, 1, 2, 3, 4, XXII, p. 81-220.

1996 : "Archaeozoological investigations in North-Eastern Italy : the exploitation of animals since the Neolithic ", Preistoria alpina, Museo Tridentino di Scienze naturali, 30, p. 43-94.
RODEI-BELLARBI I.

1989 : La faune ì Argentomagus (SaintMarcel, Indre) : élevage, artisanats et rites, thèse de doctorat nouveau régime, univ. de Paris 1-PanthéonSorbonne, 2 vol.

1993a : Fouilles de l'Institution Saint-Lazare ¿i Autun (Saône-et-Loire) : étude des ossements animaux, Service régional de l'archéologie Bourgogne, Dijon, Service archéologique d'Autun.

1993b: Place de Verdun, Tarbes (65) : étude des ossements animaux, Service régional de l'archéologie MidiPyrénées, Toulouse.

1994 : Fonilles du Lycée militaire à Autun (Saône-et-Loire) : étude des ossements animaux, Rapport d'étude, AFAN, Service régional de l'archéologie Bourgogne, Dijon, Service archéologique municipal d'Autun.

1997 : Alleins, Tamberlette: étude de la faune, Rapport d'étude, Service régional de l'archéologic ProvenceAlpes-Côte d'Azur, Aix-en-Provence.

1998: Saint-Denis : les os travaillés de la fosse 976 de l'aire 17, Rapport d'étude, Centre municipal d'archéologie, Saint-Denis.

Rovet R., FoREST V.

1995 : La villa de Saint-Romain-de-Jalionas (Isère), Rapport intermédiaire, Service régional de l'archéologie Rhône-Alpes, Lyon.

\section{ROZIER F.}

1783-1805: Cours complet d'agriculture, Paris, 12 t.

RUINÉ-LACABE S.

1992 : L'Hospitalet-du-Larzac, La Vayssière, autoroute A.75 (Aveyron), Document final de synthèse, Service régional de l'archéologie Midi-Pyrénées, Toulouse.

SC.HNEIDER L., FOREST V.

1997 : Plaissan-les-Termes (Hérault), $V I^{\prime}$ $X I^{\prime}$ siècle, Document final de synthèse en cours, AFAN, Service régional de l'archéologie Languedoc-Roussillon, Montpellier.

SERRES O. DE

1804-1805 (rééd. 1996) : Le théâtre d'agri- culture et ménage des champs, Arles, Actes Sud, $1459 \mathrm{p}$.

SPEIIIFR A., Forlist V.

1996 : Le chantier archéologique du Bouleoard périphérique nord de Iyon (Rhône), Document final de synthèse, AFAN, Service régional de l'archéologie Rhône-Alpes, Lyon.

Toledo I Mur A., Petrtot H., GARDEISEN A.

1998 : « Cabariot, Mortantambe (Charente) ", in Laporte L. (coord.), L'estuaire de la Charente de la Protohistoire au Moyen Âge, Document d'archéologie française, 72, p. 124-129.

Vaginay M., Glichari) V., Vila E.

1988 : L'habitat gaulois de Feurs (Loire), Documents d'archéologic française, 14, p. 171-185.

VAN OSSEl. P., BRCNET-VILATTE F., Cargneili. C., Charniot C.-P., Ciezar P., Coste M.-C., DeyberPersignat D., Gitta C., Gonzalez V., Lantada-Zar\%osa M., Lenharto P., Marcille C., Monnet C., Navecth A., Pieters M., Ravoire F., RodetBEIARBII.

1991 : Les Jardins du Carrousel à Paris, fouilles 1989-1990. Le rapport de l'équipe, Document final de synthèse, AFAN, Service régional de l'archéologie Île-de-France, 6 vol.

VAN OSSEl. P., Brunet-VILATTE F., Ciezar P., Coste, M.-C., Gitta C., Gonzal.z. V., Marcill. C., NavecthDomin A., Pieters M., Ravolre F., Rodet-Belarbi I., Trombetta P.-J.

1998 : Les Jardins du Carrousel (Paris). De la campagne à la ville: la formation d'un espace urbain, Document d'archéologie française, 73, p. 251-255.

Vermeulen C., Forest V.

1997 : Lot 21, Mondragon, "Les Brassières ", Vaucluse (84), Document final de synthèse, AFAN, Service régional de l'archéologie ProvenceAlpes-Côte d'Azur; Aix-en-Provence. 
VILLEDIEU F

1990 : Lyon Saint-Jean, les fouilles de l'av. Adolphe-Max, Documents d'archéologie en Rhône-Alpes, 3, série 2, p. 190.
VIIILEROY F.

Ca. 1860: L'éleveur de bêtes à corne, Librairie agricole de la maison rustique, $431 \mathrm{p}$.
WILCKENS M.

1878: «Ueber die Schädelknochen des Rindes aus dem Pfahlbau des Laibacher Moores ", Milteilungen der Anthropologischen Ciesellschaft in Wien, 7, p. 165. 